\title{
Measurement and Investigation on 1-D Consolidation Permeability of Saturated Clay considering Consolidation Stress Ratio and Stress History
}

\author{
Le Zhang $\mathbb{D}^{1},{ }^{1}$ Faning Dang $\mathbb{D},{ }^{1,2,3}$ Jun Gao, $^{1}$ and Jiulong Ding ${ }^{1}$ \\ ${ }^{1}$ School of Civil Engineering and Architecture, Xi'an University of Technology, Xi'an 710048, China \\ ${ }^{2}$ State Key Laboratory of Eco-Hydraulics in Northwest Arid Region, Xi'an University of Technology, Xi'an 710048, China \\ ${ }^{3}$ Shaanxi Key Laboratory of Loess Mechanics and Engineering, Xi'an University of Technology, Xi'an 710048, China \\ Correspondence should be addressed to Faning Dang; dangfn@163.com
}

Received 17 December 2020; Revised 19 January 2021; Accepted 4 February 2021; Published 2 March 2021

Academic Editor: Chuangzhou Wu Copyright ( $) 2021$ Le Zhang et al. This is an open access article distributed under the Creative Commons Attribution License, which
permits unrestricted use, distribution, and reproduction in any medium, provided the original work is properly cited.

\begin{abstract}
To study the influence of consolidation stress ratio and stress history on 1-D consolidation permeability of saturated clay, onedimensional consolidation permeability tests were carried out with GDS triaxial device. The results indicated that the permeability coefficient and void ratio of normally and overconsolidated saturated clay decreased with the increase of consolidation stress ratio under different consolidation stress ratios but the same stress history. And the amount of final sample's compression increased with the increase of the consolidation stress ratio. Under the condition of the same consolidation stress ratio but different stress history, the amount of final compression of the overconsolidated saturated clay was smaller than that of the normally consolidated saturated clay. Besides, the stress difference $\sigma_{d v}$ between consolidation pressure $\sigma$ and gravity stress $\sigma_{c z}$ was fitted to the amount of the final sample's compression, and a good linear relationship between the stress difference $\sigma_{d v}$ and the amount of the final sample's compression under each consolidation pressure was obtained. The results showed that it is necessary to consider the influence of consolidation stress ratio and stress history simultaneously on 1-D consolidation permeability of saturated clay. Meanwhile, it can accurately predict the amount of the final sample's compression after knowing the gravity stress. Moreover, a model prediction analysis was conducted on the saturated clay and recommended to use the modified Kozeny-Carman's equation to predict the permeability coefficient of Luochuan saturated clay during one-dimensional consolidation.
\end{abstract}

\section{Introduction}

Saturated clay (especially soft soil) has a considerable areal distribution range in China's coastal and inland areas. Due to the fact that soft clay foundation has the characteristics of high compressibility and low permeability, the duration of consolidation deformation tends to be longer. Therefore, the prediction of foundation settlement and settlement rate has become a major problem in engineering design [1]. In recent years, some new foundation improvement methods have been proposed, such as biogrouting and drainage powder sprayed piles $[2,3]$. And the relationship between the foundation settlement and the time is always based on the one-dimensional Terzaghi's consolidation theory. The theory assumed that the permeability coefficient $k$, initial void ratio $e$
, and compressibility coefficient $a$ are all constant during the consolidation process, and the permeability of water in the soil obeys Darcy's law. However, some simplified assumptions are often not met in actual projects and can be extremely complicated. Davis and Raymond [4] obtained the analytical solution of the one-dimensional nonlinear consolidation equation. And Xie et al. [5] proposed an analytical solution for one-dimensional nonlinear consolidation of double-layered soils based on Davis. A method for simulating nonlinear characteristics of soil during compression by the hyperbolic curve was developed according to the compression behavior of soil [6]. Dumais and Konrad [7] established a one-dimensional model for the consolidation of thawed soil by using the relationship among effective stress, void ratio, and permeability coefficient. Yin and Feng $[8,9]$ stated that the 
variable compressibility must be considered in settlement calculation of soft soil stratum and proposed a new simplified method to calculate the settlement of a thick soil layer by considering the nonlinear compressibility. Besides, a onedimensional nonlinear consolidation theory considering the thermal effect was established, which showed that the pore water dissipation rate or consolidation rate considering the secondary consolidation and temperature was higher than that when only considering secondary consolidation [10]. Some researchers have also conducted one-dimensional consolidation nonlinear studies on layered foundations. Xia et al. [11] assumed that the change in compressibility and permeability of the soil during the consolidation process was proportional, and the analytical solution of one-dimensional nonlinear consolidation for layered saturated soft soil was derived based on $e-\log \sigma^{\prime}$ and $e-\log k_{v}$ relations. An analytical solution for onedimension consolidation of a clay layer with variable compressibility and permeability under a ramp loading was derived based on the assumption that the initial effective stress of the clay layer remains constant with depth [12]. To consider the limitation of Terzaghi's theory, Lekha et al. [13] presented a generalized theory for the vertical consolidation of a compressible medium with finite thickness, and an analytical closed-form solution was obtained for vertical consolidation considering the variation in the compressibility and permeability. Moreover, Abbasi et al. [14] derived a onedimensional nonlinear partial differential equation for the prediction of consolidation characteristics of soft clays considering variable values for $C_{v}$ and took into consideration the changes in $C_{v}$ during consolidation.

However, the aforementioned one-dimensional nonlinear consolidation models were based on the assumption of Darcy's flow. The characteristics of the non-Darcy's flow of water in the soil during one-dimensional consolidation have long been recognized. Mishra and Patra [15], Liu et al. [16], and Zhao and Gong [17] have studied the consolidation characteristic of saturated clay by considering the non-Darcy's flow. Li et al. [18] proposed a nonlinear model of consolidation by considering the non-Darcy's flow and stress history and found that the consolidation rate of overconsolidated soil with the non-Darcy's flow was slower than that with Darcy's flow. Moreover, Terzaghi's one-dimensional consolidation equation was modified and generalized based on the non-Darcy's flow in the soil [19]. However, the consolidation theory which can consider both geometrical nonlinearity and non-Darcy's flow is rarely reported. Li et al. [20] proposed a model for soft clay, which can allow for these two factors simultaneously, and the results showed that the difference between the consolidation rates caused by the non-Darcy's and Darcy's flows is significant. Besides, some researchers have also considered the effect of stress history on the one-dimensional consolidation [21-24] and have proposed one-dimensional nonlinear consolidation equations considering stress history.

Besides, the Terzaghi's one-dimensional consolidation theory assumed that the external load is applied instantaneously and remains unchanged during the consolidation process. However, the load acting on the foundation generally increases gradually with the construction process, and it is impossible to have "instantaneous" loading as assumed by Terzaghi. Schiffman [25] gave a theoretical solution to this situation. Next, Olson [26] proposed the mathematical solution of the average degree of consolidation in the first-order linear loading process. In recent years, some researchers have also conducted one-dimensional consolidation analysis under ramp loading mode according to different working conditions. Liu and Ma [27] studied the one-dimensional consolidation of soft ground with impeded boundaries under a depth-dependent ramp load. Similarly, Sun et al. [28] also introduced the exponentially time-growing drainage boundary and investigated the one-dimensional consolidation problem of soil under a ramp load. This one-dimensional consolidation theory can be utilized to describe the asymmetric drainage characteristics of the top and bottom drainage surfaces of the actual soil layer. However, the present solution is just for homogeneous soil. Tian et al. [29] obtained an analytical solution of excess pore-water pressure under a multistage load and the continuous drainage boundary. A different conclusion from Terzaghi's one-dimensional consolidation theory was obtained; that is, the degree of consolidation is also related to the applied time-dependent load. In the same year, a new simplified method was developed to calculate the settlement of multilayer soft soils exhibiting creep subjected to the multistage loading under a onedimensional straining condition [30]. The advantage of this new simplified method is that the soft soils at both the normally consolidated state and overconsolidated state are considered in this approach by the "equivalent time" concept.

For further studying the nature of saturated clay permeability and consolidation, many researchers conducted laboratory tests on saturated clay. Experiments on the change characteristics of soil permeability coefficient under different head pressures were carried out and obtained that the permeability coefficient of soft soil decreased with the decreased of void ratio [31]. The consolidation and permeability combined tests of Xiaoshan soft clay were carried out by Qi [32] and showed that the compressibility and permeability of overconsolidated soils vary nonlinearly with the consolidation pressure during consolidation. Besides, Wen [33] had studied the one-dimensional consolidation theory of double-layered soil considering effects of stress history and revealed that the settlement was smaller and the rate of consolidation was greater than that of the one without considering the effects of the stress history. Moreover, the initial static stress state of the natural foundation soil; i.e., consolidation stress $\sigma_{1}$ and $\sigma_{3}$ or consolidation stress ratio $K_{c}$, where $K_{c}=\sigma_{1} / \sigma_{3}$, is also different. The effect of consolidation stress ratio on the pore pressure characteristics of saturated undisturbed loess under different stress paths was studied and showed that the effect of stress path on pore pressure characteristics during equal pressure consolidation was significantly different from that during $K_{0}$ consolidation [34].

Through reviewing the relevant studies, it was found that the influence of the initial stress state (consolidation stress ratio $K_{c}$ ) and stress history of natural foundation soil on the one-dimensional consolidation and permeability characteristics of saturated clay was rarely considered and only involved the properties of normally consolidated soil or overconsolidated soil on the one hand. In this study, the GDS-advanced consolidation device was utilized to conduct a series of one- 
dimensional consolidation-permeability combined tests under ramp loading on the loess silty clay in Luochuan, Shaanxi. Then, the effects of consolidation stress ratio and stress history on one-dimensional consolidation permeability of saturated clay were explored based on test results. Finally, a model prediction analysis was performed which is aimed at selecting a model suitable for predicting the permeability coefficient of Luochuan saturated clay.

\section{Test and Method}

2.1. Sample Preparation and Method. The clay soil samples used in this study were loess-like silty clay taken from Luochuan, Shaanxi. The sampling depth is $7-8 \mathrm{~m}$, and the main physical properties of the silty clay are illustrated in Table 1 .

Due to the heterogeneity of undisturbed clay samples, the samples used in this study were all saturated homogeneous remolded soil samples, and the preparation processes were as follows:

(1) Firstly, the soil was air-dried, ground, and sieved through a $2 \mathrm{~mm}$ sieve. Then, the air-dried moisture content was measured after fully mixing. The soil was prepared to a moisture content $(11.6 \%)$ that can be used for sample preparation. Finally, the prepared soil was placed in a plastic bag and sealed for 24 hours to allow moisture equalization

(2) The moisture content of the prepared soil sample was measured, and the mass of soil required for sample preparation was calculated. In this study, the pressure sampling method was used for sample preparation, and the samples with $3.91 \mathrm{~cm}$ in diameter and $8 \mathrm{~cm}$ in height were used. The sample was divided evenly into five layers during sample preparation. For making better contact between the sample layers, the contact surface should be shaved before each compaction. According to the $e$-log $p$ curve, the preconsolidation pressure of Luochuan silty clay was $115 \mathrm{kPa}$, and the soil was considered to be in a normally consolidated state. Therefore, the remolded soil samples were consolidated under a pressure of $115 \mathrm{kPa}$. After the consolidation was completed, the soil samples were considered to be in a normally consolidated state

(3) To reflect the influence of consolidation stress ratio on one-dimensional consolidation permeability of saturated clay, a consolidation test was conducted under the condition of $K_{c}=1.5$ firstly, and it was obtained that the amount of soil compression reached $10 \mathrm{~mm}$ when the consolidation stress was $600 \mathrm{kPa}$. According to the Chinese standard for the geotechnical testing method (GB/T 50123; National Standards of People's Republic of China 2019), the sample was considered to be damaged when the strain reaches $15 \%$. Therefore, the consolidation stress ratio was taken as $1,1.3$, and 1.5 , respectively
2.2. Experimental Device. A GDS triaxial device imported from the UK was used for the one-dimensional consolidation and permeability tests, as shown in Figure 1. The test device can not only perform traditional consolidation tests but also perform permeability tests under the condition of the constant consolidation pressure, which can directly measure the permeability coefficient under various consolidation stress levels. For conducting the consolidation permeability test for saturated remolded soil samples, a set of saturated soil base and dual-channel sample cap was redesigned and processed to achieve the connection of back pressure controller with sample's base and cap, which ensured that the water drained from the upper and lower ends of the sample was drained into the back pressure controller. Hence, the sample's volume change can be accurately measured. The schematic diagram of the GDS device was shown in Figure 2.

2.3. Test Procedure. For studying the one-dimensional consolidation permeability characteristics of saturated clays considering the initial consolidation state and consolidation stress ratio, one-dimensional consolidation permeability tests were performed. The specific test steps were as follows:

(1) Before loading the sample into the pressure chamber, the base and sample cap were vented to reduce the volume of gas entering the sample as much as possible when the sample was saturated with back pressure

(2) After completion of the sample preparation, the soil sample was saturated by the vacuum saturation method firstly and then by the back pressure. When the pore pressure coefficient $B$ was close or equal to 1 , the sample was considered to be fully saturated

(3) Then, the sample was consolidated by applying consolidation stress with a constant duration of $24 \mathrm{~h}$ at each stress level. When the pore pressure dissipated completely, the axial deformation was basically unchanged, and the volume change became stable; the consolidation was considered complete. The specific test scheme is shown in Table 2, and the schematic diagram of multistage ramp loading is shown in Figure 3. In Figure 3, $t_{j 1}-t_{j 4}$ represented the time required to reach each level of load, and $t_{j 1}-t_{j 4}=30$ mins. $t_{1}-t_{4}$ represented the total duration of consolidation at each stage, and $t_{1}=t_{2}=\cdots=t_{4}=24 \mathrm{~h}$

(4) Subsequently, the permeability test was performed by the water head difference formed by the back pressure and the bottom pressure. To ensure that the effective stress acting on the soil sample remains unchanged in the process of the permeability test, the following equation must be satisfied between the pressure

$$
p_{1}-p_{2} \geq p_{2}-p_{3}
$$

where $p_{1}$ is confining pressure, $p_{2}$ is back pressure, and $p_{3}$ is bottom pressure. The bottom pressure is always $0 \mathrm{kPa}$ in this 
TABle 1: Physical properties of intact $Q_{3}$ loess.

\begin{tabular}{lccccccc}
\hline \multirow{2}{*}{ Specific gravity $G_{s}$} & $\begin{array}{c}\text { Water content } \\
w(\%)\end{array}$ & $\begin{array}{c}\text { Dry density } \\
\rho_{d}\left(\mathrm{~g} / \mathrm{cm}^{3}\right)\end{array}$ & $\begin{array}{c}\text { Liquid limit } \\
w_{L}(\%)\end{array}$ & $\begin{array}{c}\text { Plastic limit } \\
w_{P}(\%)\end{array}$ & \multicolumn{3}{c}{ Particle size fraction (\%) } \\
\hline 2.7 & 13.3 & 1.34 & 28.4 & 19.2 & 4 & 73 & 23 \\
\hline
\end{tabular}

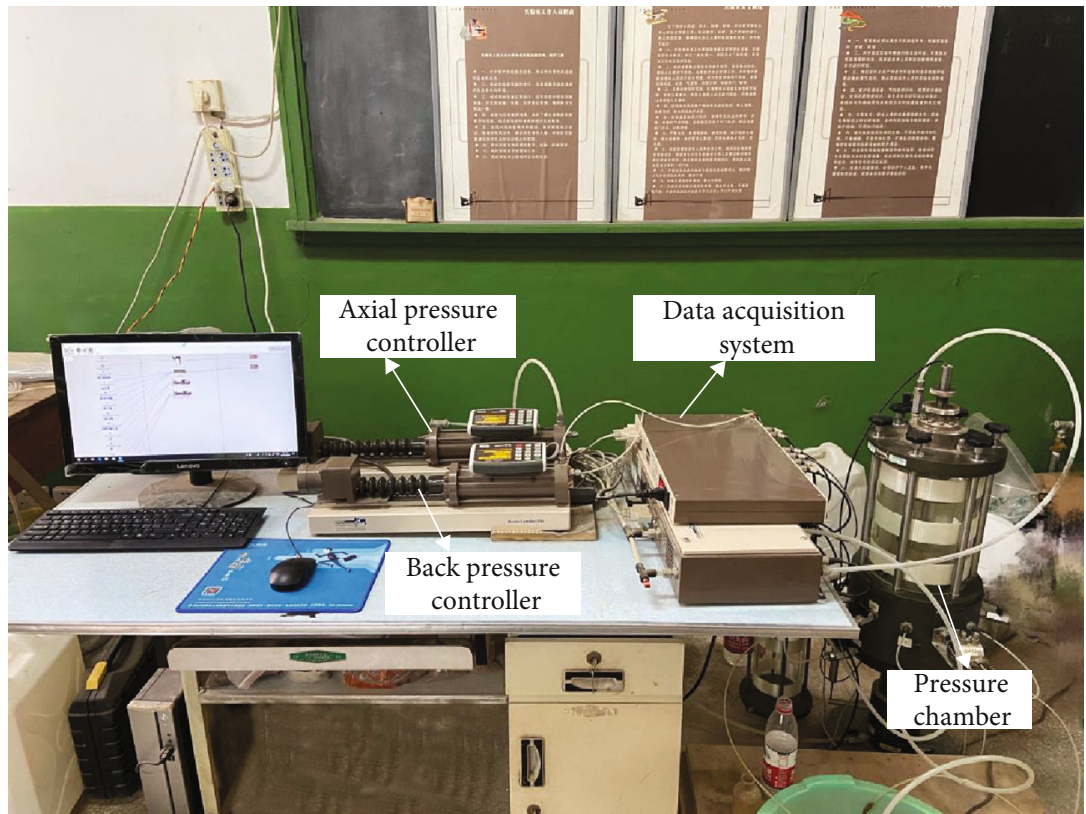

FIGURE 1: GDS triaxial device.

study, and the duration of permeability induced from water head difference is $70 \mathrm{~min}$. The test plan is listed in Table 3.

To study the influence of stress history on the onedimensional consolidation permeability of saturated clay, the consolidation stress with the same increment was applied. In this study, the double-drainage condition was adopted, and the one-dimensional consolidation diagram of the saturated clay layer is shown in Figure 4.

\section{Result and Discussion}

\subsection{Effect of Consolidation Stress Ratio on One-Dimensional Consolidation Permeability of Normally Consolidated Saturated Clay}

3.1.1. Permeability Test Results and Analysis. When the consolidation stress ratio $K_{c}=1,1.3$, and 1.5 , the relationship curves of permeability coefficient $k$ and void ratio $e$ with consolidation stress $\sigma$ in one-dimensional consolidation permeability of normally consolidated soil are shown in Figures 5 and 6 , respectively.

It can be seen from Figure 5 that the initial permeability coefficients at three consolidation stress ratios were the same before applying consolidation stress. The permeability coefficient $k$ decreased with the increase of consolidation stress, which was independent from the consolidation stress ratio. And the permeability coefficient decreased as the consolidation stress ratio increased under the same consolidation stress. On the whole, the permeability coefficient showed a nonlinear decreasing trend with the increase of consolidation stress. As the consolidation stress continued to increase, the rate at which the permeability coefficient $k$ decreased as the consolidation stress increased gradually slows down.

The consolidation stress ratio $K_{c}$ had a certain effect on the permeability coefficient $k$. As the consolidation stress increased, the smaller the consolidation stress, the greater the effect of the consolidation stress ratio on the permeability coefficient. Besides, the permeability coefficient is an important parameter for the consolidation analysis of saturated clay. Therefore, it is necessary to study the consolidation stress ratio on one-dimensional consolidation permeability of saturated clay.

In the one-dimensional consolidation process of saturated clay, the determination of the void ratio $e$, compression coefficient $a_{v}$, and compression modulus $E_{s}$ is the same as the traditional consolidation test method.

The void ratio $e_{i}$ of the sample after consolidation stability under various consolidation pressures can be obtained from

$$
e_{i}=e_{0}-\left(1+e_{0}\right) \cdot \frac{\sum \Delta h_{i}}{h_{0}}
$$

where $e_{0}$ and $h_{0}$ are the void ratio and initial height of the sample after back pressure saturation, $e_{i}$ is the void ratio of the sample after consolidation stability, and $\sum \Delta h_{i}$ is the cumulative compression of the sample at the level of 


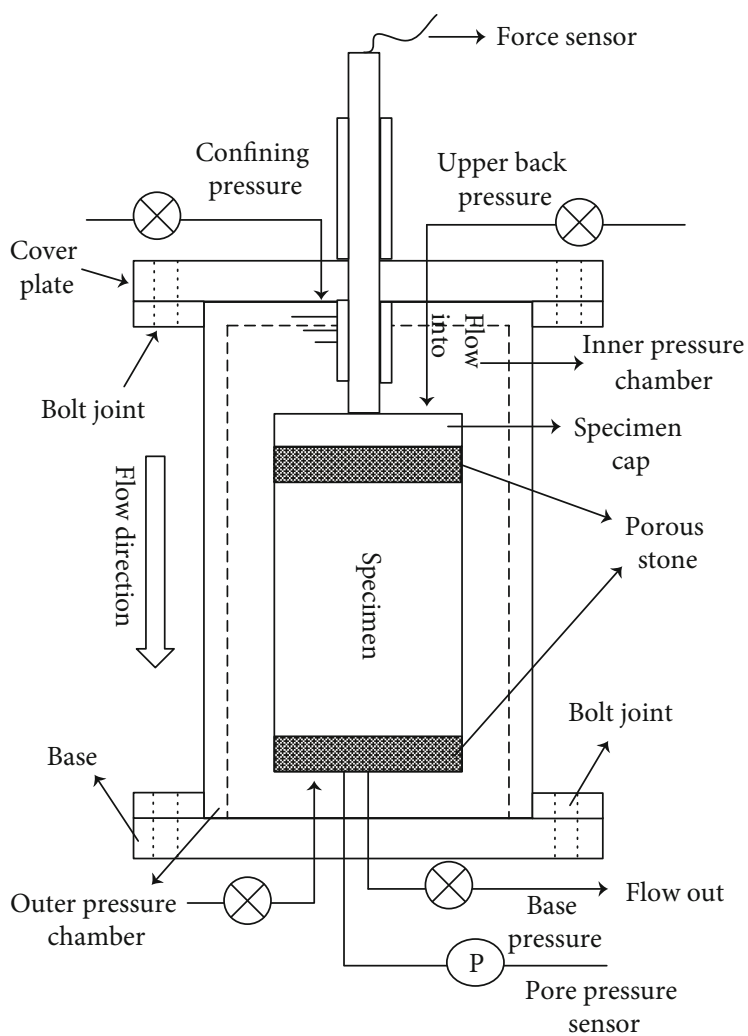

FIGURE 2: Schematic diagram of pressure application for consolidation and permeability tests.

TABLE 2: Scheme and procedure of staged consolidation test.

\begin{tabular}{lc}
\hline Consolidation state & \multicolumn{1}{c}{ Loading step } \\
\hline Normally consolidated & $115 \rightarrow 140 \rightarrow 165 \rightarrow 190 \rightarrow 215 \mathrm{kPa}$ \\
Overconsolidated & $115 \rightarrow 25 \rightarrow 50 \rightarrow 75 \rightarrow 100 \mathrm{kPa}$ \\
\hline
\end{tabular}

consolidation stress $\sigma_{i}$. Then, the height of the sample after compression is expressed by

$$
h=h_{0}-\sum \Delta h_{i}
$$

The compression coefficient $a_{v}$ in a certain stress range can be yield by

$$
a_{v}=\frac{e_{i}-e_{i+1}}{\sigma_{i+1}-\sigma_{i}}
$$

where $e_{i}$ and $e_{i+1}$ are the void ratios corresponding to $\sigma_{i}$ and $\sigma_{i+1}$, respectively, $\sigma_{i}$ and $\sigma_{i+1}$ are the consolidation stress values of a certain level and the next level, respectively.

The compression modulus $E_{s}$ in a certain stress range can be obtained by

$$
E_{s}=\frac{1+e_{0}}{a_{v}}
$$

According to Equations (2), (3), (4), and (5), the deformation parameters of the sample during the consolidation process are illustrated in Table 4. The definition of each parameter in Table 4 was the same as above. For example, the amount of compression, void ratio, compressibility, and compression modulus of the corresponding sample under the consolidation stress of $165 \mathrm{kPa}$ were the calculated results of various parameters within the range of consolidation stress of $140-165 \mathrm{kPa}$.

In this study, the void ratio after back pressure saturation was taken as the initial void ratio $e_{0}$ of the sample. It can be seen from Figure 6 that the corresponding initial void ratio $e_{0}$ when $K_{c}=1,1.3$, and 1.5 was 1.015. It also can be seen from Equation (2) that the void ratio $e$ during the consolidation stage is related to the initial void ratio $e_{0}$, initial height $h_{0}$ , and the cumulative compression of the sample $\sum \Delta h_{i}$ under certain consolidation stress.

From Figure 6, the void ratio decreased with the increase of consolidation stress. When $\sigma=215 \mathrm{kPa}$, the corresponding void ratios of $K_{c}=1.0,1.3$, and 1.5 were $0.904,0.876$, and 0.834 , respectively. After obtaining the amount of sample's compression, the variation curve of void ratio and time can be drawn, which is shown in Figure 7.

Both Figures 5 and 6 show the nonlinear characteristics of the soil sample during the consolidation process. As increased with the consolidation stress, the pore volume of the soil decreased continuously due to the drainage of pore water, which resulted in the permeability coefficient of the soil was continuously decreasing. The reduction of the void ratio was also related to the consolidation stress ratio $K_{c}$ to a certain extent. When $K_{c}=1,1.3$, and 1.5, the corresponding reductions for the void ratio were $10.97 \%, 13.70 \%$, and $17.79 \%$, which illustrated the importance of considering the consolidation stress ratio on one-dimensional consolidation permeability of saturated clay in this study.

It can be seen from Figure 7 that the void ratio $e$ showed a stepwise downward trend with time. The void ratio of the sample hardly changes during the permeability stage, and the change of the sample's void ratio mainly occurred during the consolidation stage.

3.1.2. Consolidation Test Results and Analysis. The consolidation coefficient is an important parameter in both geotechni$\mathrm{cal}$ and geoenvironmental engineering [35]. According to the Terzaghi's one-dimensional consolidation theory, the consolidation coefficient of the sample can be obtained according to

$$
C_{v}=\frac{k\left(1+e_{1}\right)}{a_{v} \cdot \gamma_{w}}
$$

where $C_{v}$ represents the consolidation coefficient of the soil $\left(\mathrm{cm}^{2} / \mathrm{s}\right) ; k$ is the permeability coefficient $(\mathrm{cm} / \mathrm{s}) ; e_{1}$ is the initial void ratio; $a_{v}$ is the compression coefficient in a certain consolidation stress range $\left(\mathrm{MPa}^{-1}\right)$; and $\gamma_{w}$ is the unit weight of water (chosen as $10 \mathrm{kN} / \mathrm{m}^{3}$ ). In this study, the initial void ratio and the initial height were determined by assuming that the completed state of the previous level of stress consolidation is the initial state of this level. 


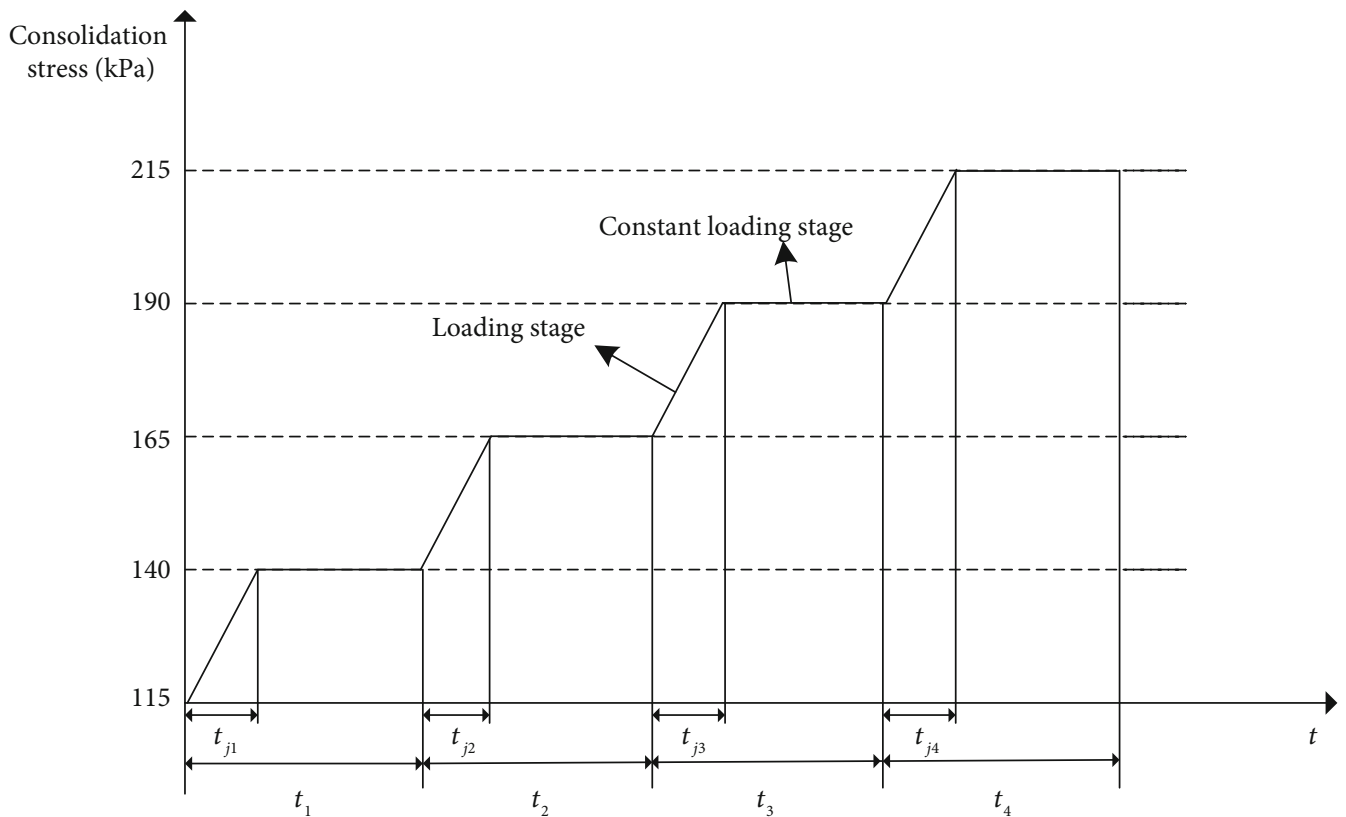

FIGURE 3: Schematic diagram of multistage ramp loading.

TABle 3: Permeability test scheme.

\begin{tabular}{lcc}
\hline $\begin{array}{l}\text { Consolidation } \\
\text { state }\end{array}$ & $\begin{array}{c}\text { Consolidation stress } \\
(\mathrm{kPa})\end{array}$ & $\begin{array}{c}\text { Water head difference } \\
(\mathrm{kPa})\end{array}$ \\
\hline & 25 & 5,10 \\
Overconsolidated & 50 & 10,20 \\
& 75 & 10,20 \\
& 100 & 20,40 \\
\hline \multirow{3}{*}{ Normally } & 140 & $20,40,60$ \\
consolidated & 165 & $20,40,60,80$ \\
& 190 & $20,40,60,80$ \\
& 215 & $20,40,60,80,100$ \\
\hline
\end{tabular}

According to Equation (6), the consolidation coefficients of the sample with $K_{c}=1,1.3$, and 1.5 are shown in Table 5 . Following Table 5, the $C_{v}-\sigma$ relationship curve was plotted with the consolidation stress $\sigma$ as the abscissa and the consolidation coefficient $C_{v}$ as the ordinate, which is shown in Figure 8.

It can be seen from Figure 8 that when $K_{c}=1,1.3$, and 1.5, the consolidation coefficient $C_{v}$ showed a trend of increasing first and then decreasing with the increase of consolidation stress. Some researchers have also studied the changing law of consolidation coefficient with consolidation stress and time during the process of consolidation [14, 36]. It was found that with the increase of consolidation stress, the change of consolidation coefficient was not only monotonously increasing or decreasing. Li et al. [36] established the consolidation coefficient expression related to pore development and revealed that the development of the sample pore greatly affected the changing law of the consolidation coefficient. In the consolidation process, the consolidation

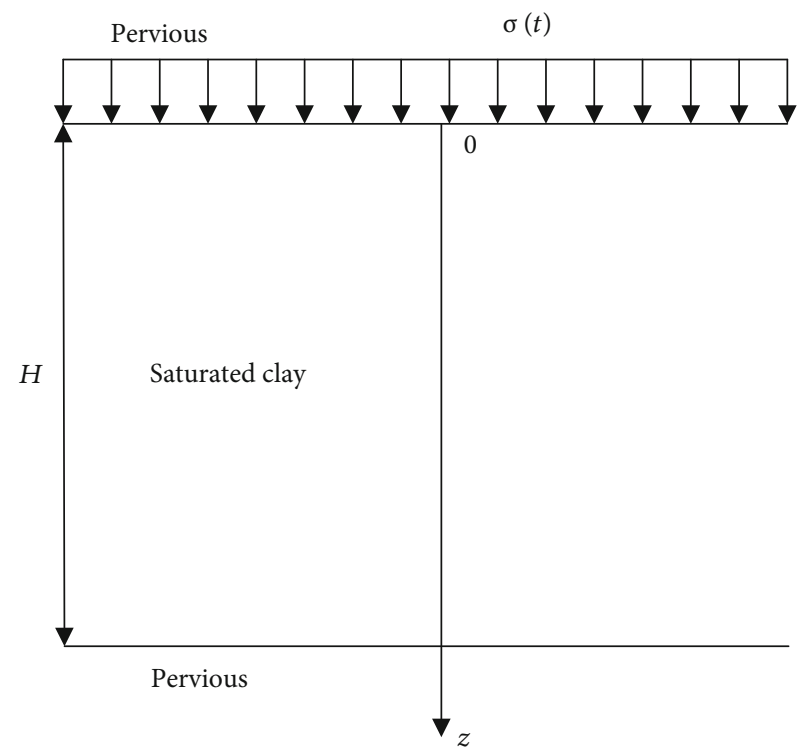

FIgURE 4: One-dimensional consolidation sketch.

coefficient of the soil was a variable, which was related to the effective stress acting on the soil sample. The consolidation coefficient was an increasing function relative to the void ratio under a relatively lower effective stress level. With the soil sample being further compressed, the void ratio continued to decrease, which resulted in a decrease in the consolidation coefficient. As shown in Figure 8, the consolidation stress ratio had an obvious influence on the consolidation coefficient, but it did not affect the distribution shape of the consolidation coefficient. The larger the consolidation stress ratio, the smaller the consolidation coefficient.

The relationship curve between the amounts of sample's compression and time is shown in Figure 9. 


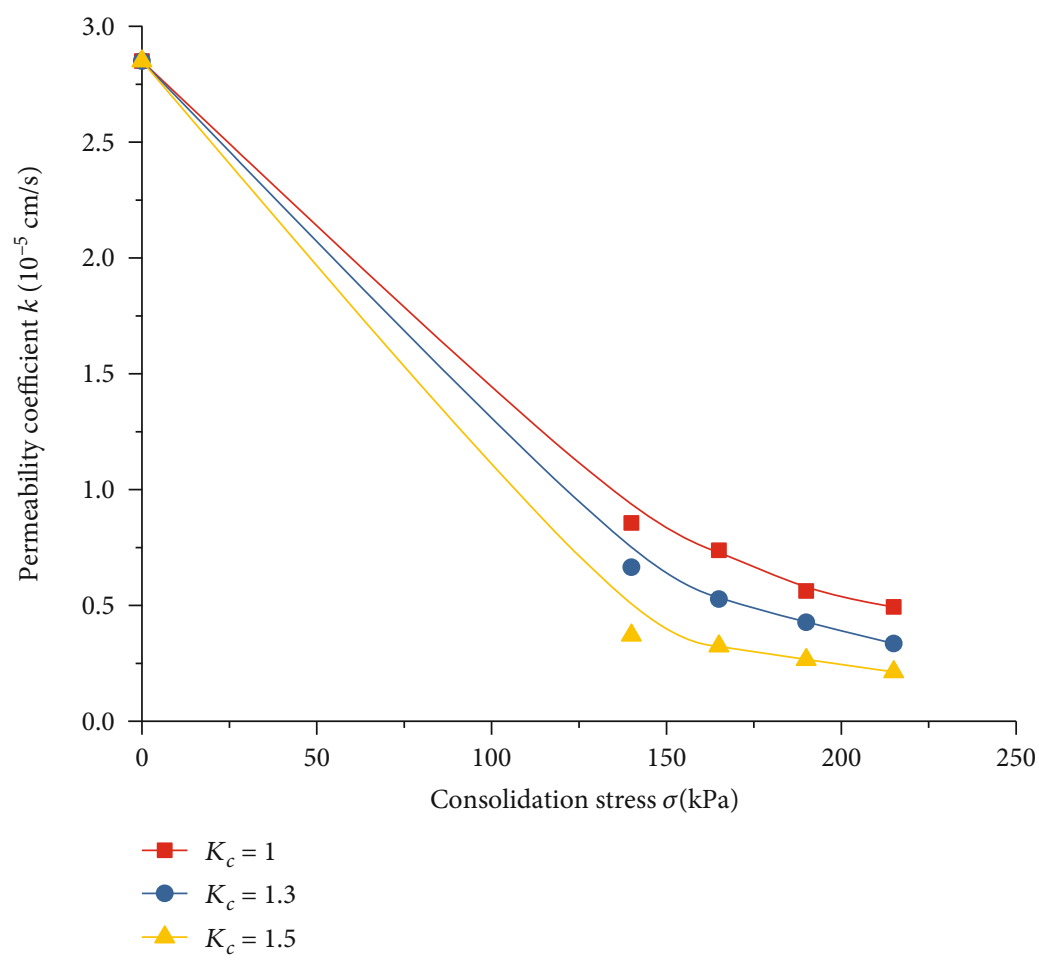

FIGURE 5: The curve of permeability coefficient of normally consolidation clay with consolidation pressure at different consolidation stress ratios.

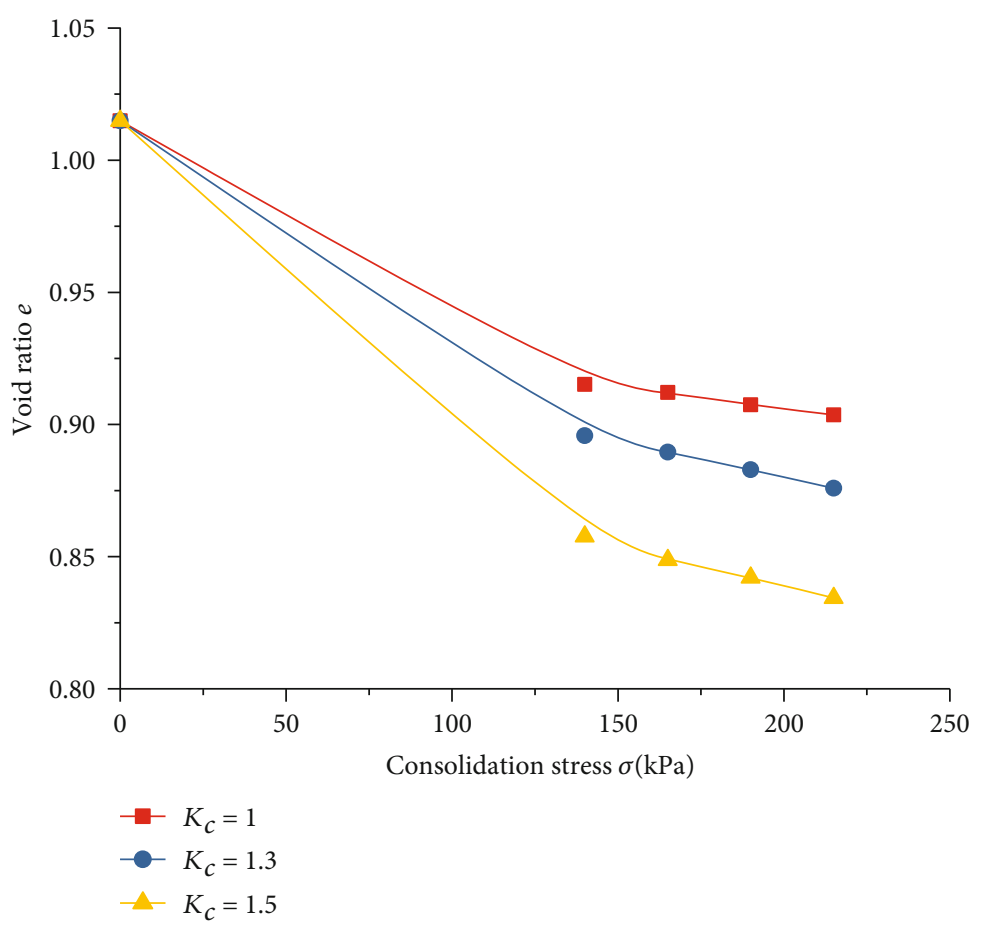

FIGURE 6: The curve of void ratio of normally consolidation clay with consolidation pressure at different consolidation stress ratios. 
TABLE 4: Calculation results of mechanical parameters of normally consolidation clay during consolidation.

\begin{tabular}{|c|c|c|c|c|c|c|}
\hline $\begin{array}{l}\text { Consolidation } \\
\text { stress ratio } K_{c} \\
\end{array}$ & $\begin{array}{c}\text { Consolidation } \\
\text { stress }(\mathrm{kPa})\end{array}$ & $\begin{array}{c}\text { Sample's } \\
\text { compression }(\mathrm{mm})\end{array}$ & $\begin{array}{c}\text { Sample's height } \\
\text { after compression }(\mathrm{mm})\end{array}$ & $\begin{array}{l}\text { Void } \\
\text { ratio } e\end{array}$ & $\begin{array}{c}\text { Compression } \\
\text { coefficient }\left(\mathrm{MPa}^{-1}\right) \\
\end{array}$ & $\begin{array}{c}\text { Compression } \\
\text { modulus } E_{s}\end{array}$ \\
\hline \multirow{4}{*}{1} & 140 & 3.96 & 76.03 & 0.915 & 0.71 & 2.83 \\
\hline & 165 & 4.08 & 75.91 & 0.912 & 0.12 & 16.46 \\
\hline & 190 & 4.27 & 75.72 & 0.907 & 0.19 & 10.72 \\
\hline & 215 & 4.43 & 75.56 & 0.904 & 0.17 & 12.16 \\
\hline \multirow{4}{*}{1.3} & 140 & 4.73 & 75.26 & 0.896 & 0.85 & 2.37 \\
\hline & 165 & 4.98 & 75.01 & 0.890 & 0.25 & 8.13 \\
\hline & 190 & 5.24 & 74.75 & 0.883 & 0.27 & 7.57 \\
\hline & 215 & 5.52 & 74.47 & 0.876 & 0.28 & 7.20 \\
\hline \multirow{4}{*}{1.5} & 140 & 6.24 & 73.75 & 0.858 & 1.12 & 1.79 \\
\hline & 165 & 6.60 & 73.39 & 0.849 & 0.36 & 5.63 \\
\hline & 190 & 6.86 & 73.13 & 0.842 & 0.27 & 7.57 \\
\hline & 215 & 7.17 & 72.82 & 0.834 & 0.31 & 6.59 \\
\hline
\end{tabular}

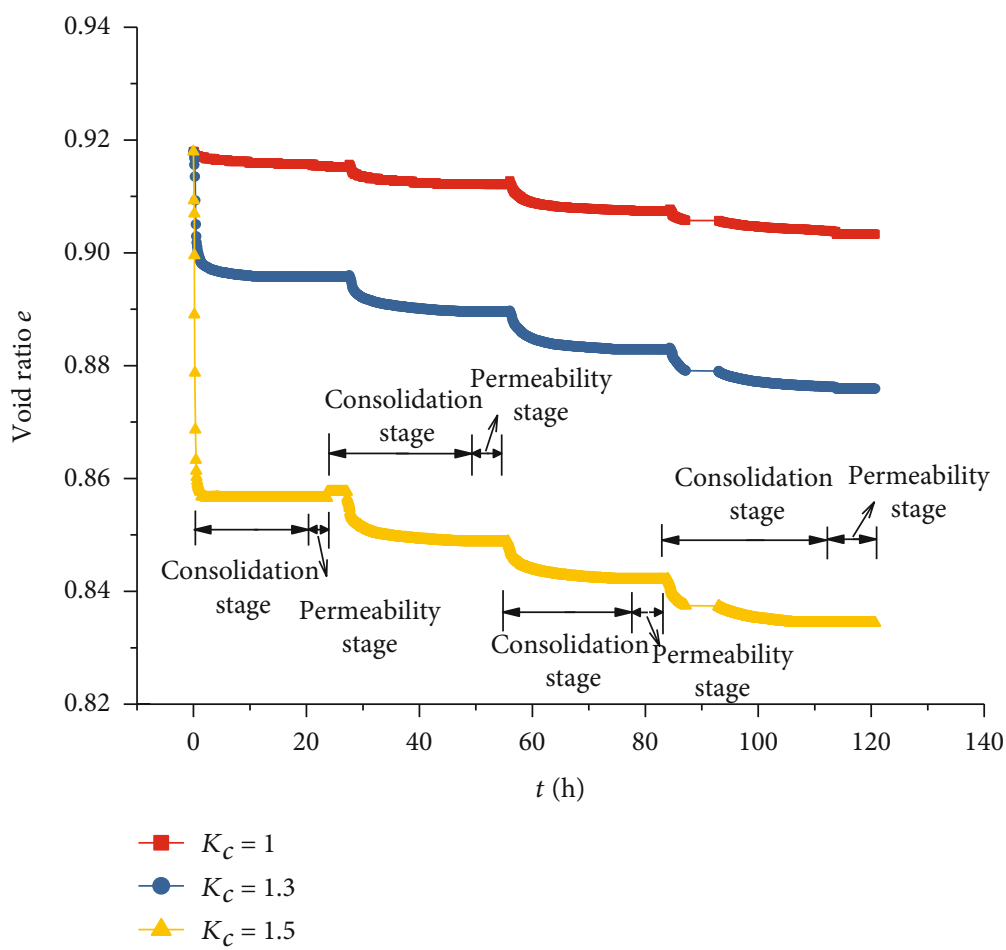

Figure 7: The curve of void ratio of normally consolidation clay with time.

It can be seen from Figure 9 that the amount of sample's compression increased stepwise with time under three consolidation stress ratios. The amount of sample's compression at the permeability stage was almost $0 \mathrm{~mm}$, and the sample's compression mainly occurred at the consolidation stage. It can also be seen from the figure that the amount of sample's final compression corresponding to $K_{c}=1,1.3$, and 1.5 were $4.43,5.52$, and $7.17 \mathrm{~mm}$, respectively. Therefore, considering the initial stress state of the soil in the one-dimensional consolidation of saturated clay plays a good role in accurately predicting the final settlement of the soil in the future.
Figure 10 displays the variation curve of the permeability coefficient of normally saturated clay with the void ratio in the logarithm coordinate. Taking the slope of the linear fitting line as permeability index $C_{k}$ and $C_{k}$ corresponding to $K_{c}=1$, 1.3 , and 1.5 was expressed by $C_{k 1}, C_{k 1.3}$, and $C_{k 1.5}$, respectively. Then, $C_{k 1}=0.047, C_{k 1.3}=0.067$, and $C_{k 1.5}=0.093$.

It can be seen from Figure 10 that the permeability coefficient $k$ of the sample decreased as the void ratio decreased. When the consolidation stress $\sigma=215 \mathrm{kPa}$, the corresponding permeability coefficients of $K_{c}=1,1.3$, and 1.5 were as follows: $0.493 \times 10^{-5} \mathrm{~cm} / \mathrm{s}, 0.335 \times 10^{-5} \mathrm{~cm} / \mathrm{s}$, and $0.213 \times 10$ 
TABLE 5: Calculated value of consolidation coefficient.

\begin{tabular}{lcc}
\hline $\begin{array}{l}\text { Consolidation } \\
\text { stress ratio } K_{c}\end{array}$ & $\begin{array}{c}\text { Consolidation } \\
\text { stress }(\mathrm{kPa})\end{array}$ & $\begin{array}{c}\text { Consolidation coefficient } \\
\left(10^{-5} \mathrm{~cm}^{2} / \mathrm{s}\right)\end{array}$ \\
\hline \multirow{3}{*}{1} & 140 & 0.230 \\
& 165 & 1.152 \\
190 & 0.571 \\
& 215 & 0.567 \\
\hline \multirow{3}{*}{1.3} & 140 & 0.148 \\
& 165 & 0.401 \\
& 190 & 0.302 \\
& 215 & 0.225 \\
\hline \multirow{3}{*}{1.5} & 140 & 0.061 \\
& 165 & 0.167 \\
& 190 & 0.184 \\
& 215 & 0.128 \\
\hline
\end{tabular}

${ }^{-5} \mathrm{~cm} / \mathrm{s}$, which was about the initial permeability coefficient $0.173,0.118$, and 0.075 times. The greater the $K_{c}$, the greater the amplitude of variation.

Figure 11 represents the relation curve of the void ratio of normally consolidated saturated clay with the consolidation stress. The compression index corresponding to $K_{c}=1,1.3$, and 1.5 was represented by $C_{c 1}, C_{c 1.3}$, and $C_{c 1.5}$. Therefore, $C_{c 1}, C_{c 1.3}$, and $C_{c 1.5}$ were equal to $0.063,0.106$, and 0.123 , respectively, where the compression index was a maximum when $K_{c}=1.5$.

It can be seen from the $e-\log \sigma$ curve in Figure 11 that the void ratio decreased as the consolidation pressure increased, and the greater the consolidation stress ratio $K_{c}$, the smaller the void ratio $e$. The test results showed the nonlinearity of the one-dimensional consolidation of the soil sample.

3.1.3. Analysis of Compression Curve. For a homogeneous soil layer with a natural gravity of $\gamma$, at any depth $z$ under the natural ground, the vertical self-weight stress $\sigma_{c z}$ of the soil is equal to the gravity of the soil column per unit area. That is,

$$
\sigma_{c z}=\sum_{\mathrm{i}=1}^{n} \gamma_{i} h_{i},
$$

where $\sigma_{c z}$ is the vertical effective self-weight stress of the soil at any depth $z$ under the natural ground $(\mathrm{kPa}) ; n$ is the total number of soil layers within the depth $z ; h_{i}$ is the thickness of the $i$ th soil layer $(\mathrm{m}) ; \gamma_{i}$ is the natural unit weight of the $i$ th soil layer; and the effective unit weight is taken for the soil layer below the groundwater level $\left(\mathrm{kN} / \mathrm{m}^{3}\right)$.

The sampling depth is 7-8 m, and its self-weight stress $\sigma_{c z}$ is in the range of $106.4 \sim 121.6 \mathrm{kN}$. The preconsolidation pressure is $115 \mathrm{kPa}$, and the soil is considered to be in the normally consolidated state. Therefore, it was determined that the self-weight stress of the sample used in the study was $115 \mathrm{kPa}$. Then, the difference $\sigma_{d v}$ between the consolida- tion pressure $\sigma$ applied in the test and the self-weight stress $\sigma_{c z}$ of the soil layer was expressed by

$$
\sigma_{\mathrm{dv}}=\sigma-\sigma_{\mathrm{cz}} .
$$

The calculated values of the difference between the consolidation pressure and the self-weight stress of the soil layer when the consolidation stress ratio $K_{c}=1$ are listed in Table 6. The fitted relation curve between the amount of sample's final compression $s_{f}$ and $\sigma_{d v}$ is shown in Figure 12.

It can be seen from Figure 12 that the stress difference $\sigma_{d v}$ had a good linear relationship with the amount of sample's final compression at each consolidation pressure. After knowing the self-weight stress of the soil, the amount of final compression of the sample can be predicted more accurately, which had an important application value to the engineering.

3.2. Effect of Consolidation Stress Ratio on One-Dimensional Consolidation Permeability of Overconsolidated Saturated Clay. As mentioned above, the preconsolidation pressure of Luochuan loess-like silty clay $\sigma_{c}$ was $115 \mathrm{kPa}$. Therefore, the consolidation stress applied to the soil sample was 25,50 , 75 , and $100 \mathrm{kPa}$, and the corresponding overconsolidation ratios (OCR) are 4.6, 2.31 .5 , and 1.2, respectively.

3.2.1. Permeability Test Results and Analysis. Table 7 shows the measured values of the permeability coefficient at various consolidation pressures for overconsolidated soil.

According to Table 7 and Equation (2), the relationship curves of permeability coefficient, void ratio, and consolidation stress at different consolidation stress ratios $K_{c}$ were drawn, which are shown in Figures 13 and 14.

As can be seen from Figures 13 and 14, for overconsolidated soils, both the permeability coefficient and the void ratio decreased with increasing consolidation pressure at different consolidation stress ratios, and the larger $K_{c}$, the smaller $e$ and $k$. Taking the consolidation stress ratio $K_{c}=$ 1.0 as an example, the permeability coefficients when the consolidation stress was 50,75 , and $100 \mathrm{kPa}$ were reduced by $24.20 \%, 26.66 \%$, and $43.48 \%$, respectively, compared with that at $25 \mathrm{kPa}$. Besides, the permeability coefficient and void ratio of overconsolidated soil decreased with the increase of the consolidation stress ratio at the same consolidation pressure. This phenomenon was the same as that of normally consolidated soil; that is, the permeability coefficient was related to the sample's void ratio, and the larger the consolidation stress ratio, the smaller the sample's void ratio.

3.2.2. Consolidation Test Results and Analysis. According to Equations (2), (3), (4), and (5), the deformation parameters of consolidation and the amount of compression of overconsolidated soils were calculated, as shown in Table 8.

According to Table 8, the relationships between the sample's void ratio and compression over time during the consolidation and compression process are shown in Figures 15 and 16.

It can be seen from Figure 15 that the amount of sample's compression increased with time during the one-dimensional consolidation of the overconsolidated soil. And the sample's compression mainly occurred during the consolidation stage. 


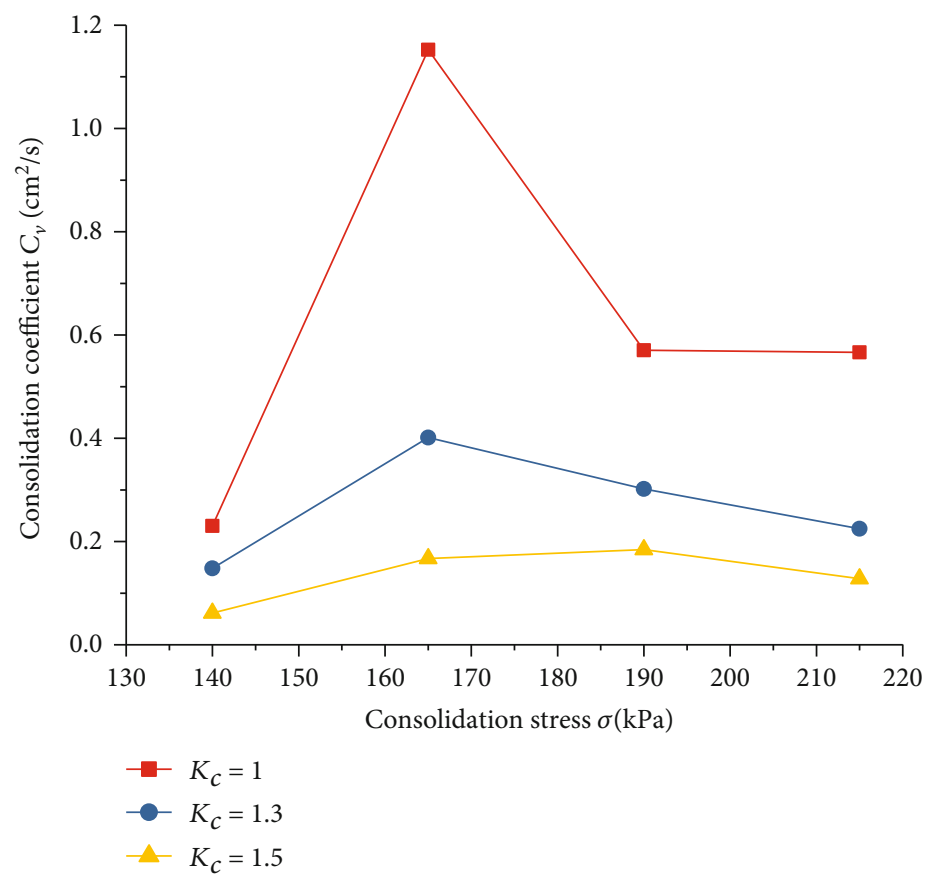

FIGURE 8: The curve of consolidation coefficients of normally consolidation clay with consolidation pressure at different consolidation stress ratios.

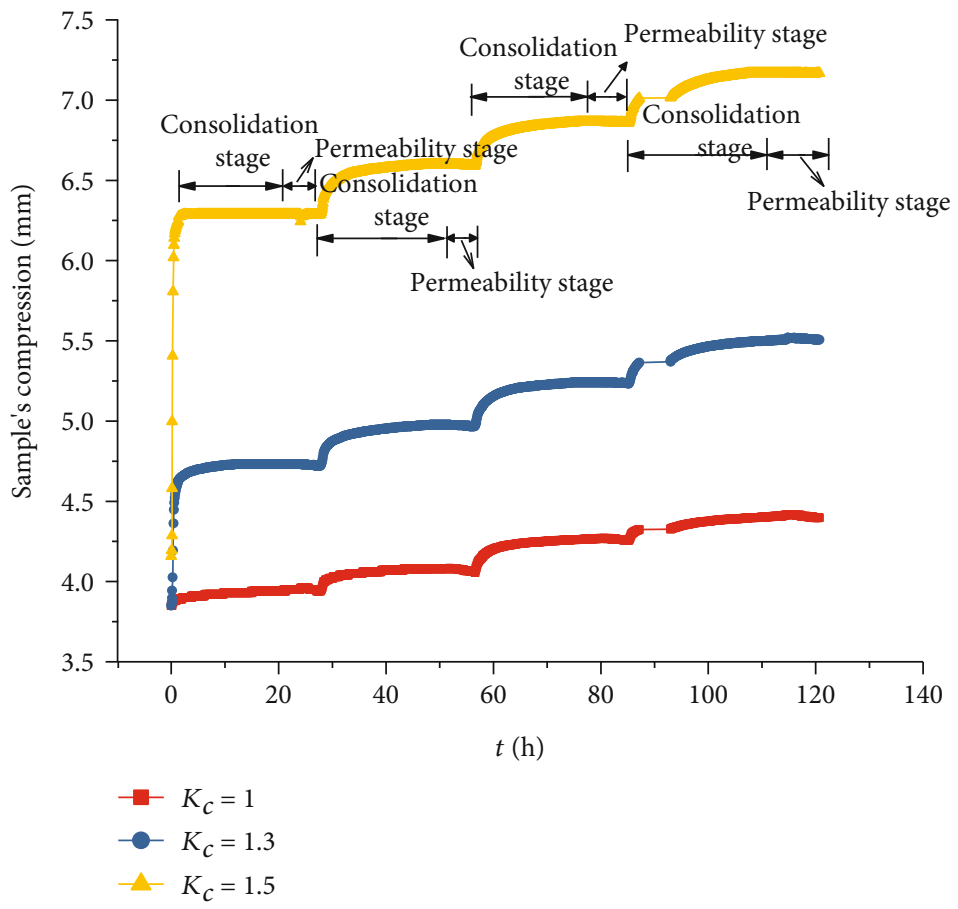

FIGURE 9: The curve of normally consolidation clay compression with time at different consolidation stress ratios. 


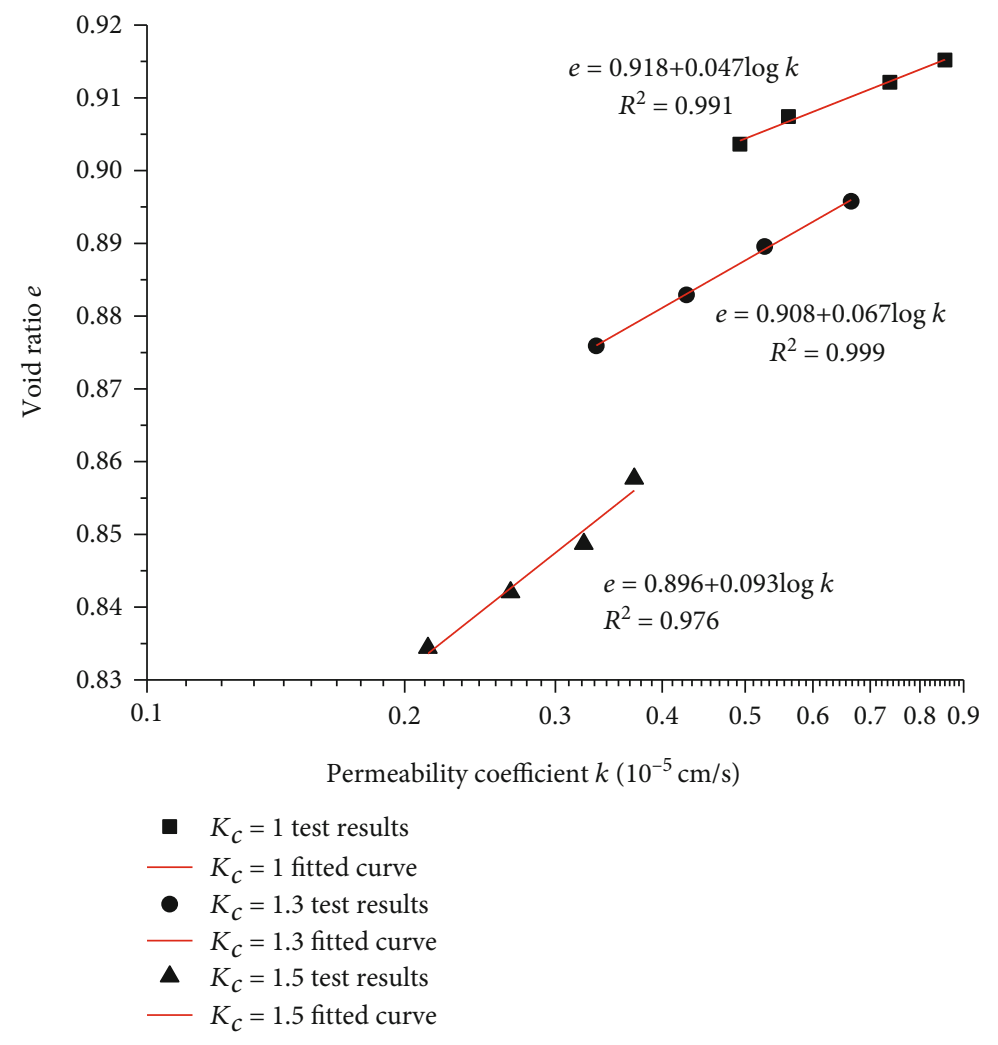

Figure 10: $e$-log $k$ curve.

Taking the consolidation stress ratio $K_{c}=1$ as an example, when the consolidation stress was $25,50,75$, and $100 \mathrm{kPa}$, the corresponding amount of sample's compression was $3.23,3.31,3.41$, and $3.53 \mathrm{~mm}$, respectively. However, the amount of sample's compression during the permeability stage under the corresponding consolidation stress hardly changed. The amount of final sample's compression varied with different consolidation stress ratios. When $K_{c}=1,1.3$, and 1.5, the amount of final sample's compression was 3.53, 3.92 , and $4.57 \mathrm{~mm}$, respectively, which revealed that the greater the consolidation stress ratio, the greater the final sample's compression.

Accordingly, from Figure 16, it can be seen that the void ratio of the sample gradually decreased with time, and the variation of the void ratio mainly occurred in the consolidation stage, while hardly changing in the permeability stage. Different consolidation stress ratios resulted in a different final void ratio of the sample. That is, when $K_{c}=1,1.3$, and 1.5 , the corresponding void ratio was $0.926,0.916$, and 0.900 , respectively. In other words, the greater the consolidation stress ratio, the smaller the final void ratio of the sample. The final void ratio was reduced by $8.76 \%, 9.73 \%$, and $11.35 \%$ compared with the initial void ratio.

3.2.3. Compression Curve Analysis. According to Equations (7) and (8), the difference between the consolidation pressure of saturated clay and the self-weight stress of the soil layer can be obtained. Only the calculated values when $K_{c}=1$ are listed in Table 9.
The relationship curve between the stress difference $\sigma_{d v}$ and the amount of final sample's compression $s_{\mathrm{f}}$ was linearly fitted, as shown in Figure 17.

It can be seen from Figure 17 that there was a good linear relationship between the stress difference of overconsolidated soil and the amount of final sample's compression under each consolidation pressure, and the amount of final compression of overconsolidated soil can be accurately predicted after knowing the self-weight stress of soil.

3.3. Effect of Stress History on One-Dimensional Consolidation and Permeability of Saturated Clay. The compressibility and permeability of soil play an important role in consolidation, which are closely related to stress history [33]. The research results showed that the settlement of the foundation was smaller and the consolidation development was faster when the stress history effect was considered. Besides, the settlement development rate increased with the increase of preconsolidation pressure.

According to the obtained test results, a series of consolidation and settlement curves of normally and overconsolidated soil under the condition of a certain consolidation stress ratio $K_{c}$ (and $K_{c}=1$ ) was acquired.

Figure 18 is the variation curve of the amount of sample's compression with the time of normally and overconsolidated saturated clay during the consolidation process when the consolidation stress ratio $K_{c}=1$. It can be seen from the figure that the amount of compression of 


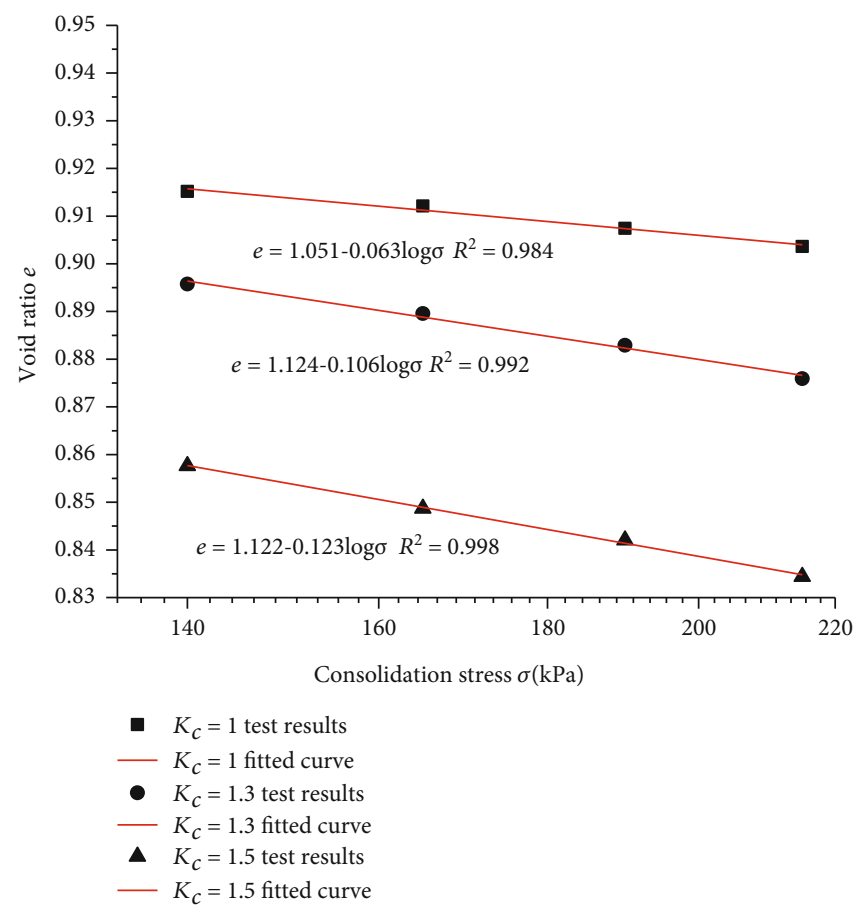

FIGURE 11: $e-\log \sigma$ curve.

TABLE 6: Stress calculations of normally consolidation clay.

\begin{tabular}{lccc}
\hline Stress state & $\sigma(\mathrm{kPa})$ & $\sigma_{c z}(\mathrm{kPa})$ & $\sigma_{d v}(\mathrm{kPa})$ \\
\hline & 140 & & 25 \\
Normally consolidated & 165 & & 50 \\
& 190 & 115 & 75 \\
& 215 & & 100 \\
\hline
\end{tabular}

overconsolidated soil was less than that of normally consolidated soil during the same consolidation time. $\mathrm{Hu}$ [37] used the semianalytical method to study the onedimensional linear and nonlinear consolidation behavior of single-layer overconsolidated saturated soil foundation. The results revealed that the settlement of the foundation was smaller and the consolidation developed faster when the influence of stress history was considered, which was consistent with the conclusion of this study. That is, the amount of final compression of the overconsolidated soil under the 5 th continuous load was $3.53 \mathrm{~mm}$, while the normally consolidated soil was $4.43 \mathrm{~mm}$.

Figures 19 and 20 are the variation curve of the void ratio $e$ and the permeability coefficient $k$ with the consolidation pressure during the process of one-dimensional consolidation permeability of normally and overconsolidated saturated clay.

It can be seen from Figure 19 that the void ratio of normally and overconsolidated clays decreased monotonously with the increase of consolidation stress during the process of one-dimensional consolidation permeability. Accordingly, the permeability coefficient decreased nonlinearly with the increase of consolidation stress. The compressibil- ity and permeability of soil in the overconsolidation stage were much less than that in the normally consolidation stage.

As can be seen from Figures 18, 19, and 20, considering the stress history was of great significance for onedimensional consolidation of saturated clay when the consolidation stress ratio $K_{c}$ was constant. However, stress history did not affect the relationship between the permeability coefficient and void ratio.

\section{Model Prediction of Saturated Clay Permeability Coefficient}

All fields of geotechnical engineering are closely related to the permeability of rock and soil [38, 39]. In engineering practice, it is particularly important to accurately and quickly predict the permeability coefficient of saturated clay. The previous section proposed that stress history did not affect the relationship between permeability coefficient and void ratio; thus, only the permeability coefficient of normally consolidated saturated clay was predicted in this section. The study selected the prediction equations of permeability coefficient considering the initial consolidation state proposed by Gao et al. [40], Stokes flow permeability coefficient equation, and consolidation degree permeability equation to predict the permeability coefficient of saturated clay in Luochuan, Shaanxi.

(1) When expressed by the permeability coefficient prediction equations proposed by Gao et al. [40], there were 


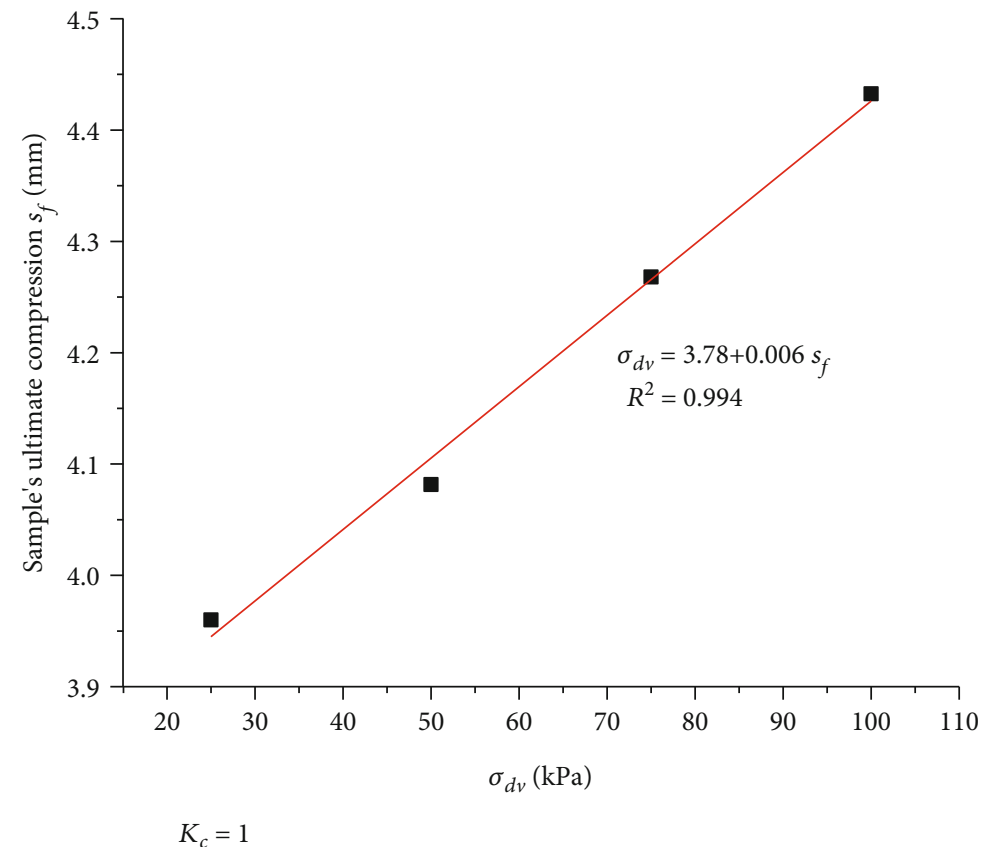

- Test results

- Fitted curve

Figure 12: The relation curve between soil ultimate compression and stress difference.

$$
\begin{gathered}
k=k_{0} \frac{1+e_{0}}{e_{0}^{2}} \frac{\left(e_{0}-C_{c} \lg \left(\left(\sigma_{0}+\Delta \sigma\right) / \sigma_{0}\right)\right)^{2}}{1+e_{0}-C_{c} \lg \left(\left(\sigma_{0}+\Delta \sigma\right) / \sigma_{0}\right)}, \\
k=k_{0} \frac{1+e_{0}}{e_{0}^{3}} \frac{\left(e_{0}-C_{c} \lg \left(\left(\sigma_{0}+\Delta \sigma\right) / \sigma_{0}\right)\right)^{3}}{1+e_{0}-C_{c} \lg \left(\left(\sigma_{0}+\Delta \sigma\right) / \sigma_{0}\right)} .
\end{gathered}
$$

Equations (9) and (10) were the permeability coefficient prediction equations for normally consolidated soil based on the Darcy's permeability coefficient equation and the Kozeny-Carman's permeability coefficient equation, respectively, where $k_{0}$ and $e_{0}$ are the initial permeability coefficient and void ratio of the soil, respectively

(2) When expressed by the Stokes flow permeability coefficient equation, there was

$$
k=\frac{\gamma_{w z} R^{2} e}{8 \eta(1+e)},
$$

where $R$ is the radius of the capillary $(\mathrm{cm}) ; \eta$ is the dynamic viscosity coefficient of free water $\left(\mathrm{g} \cdot \mathrm{s} \cdot \mathrm{cm}^{-2}\right) ; \gamma_{w z}$ is the weight of free water $\left(\mathrm{kN} / \mathrm{m}^{3}\right)$; and $e$ is the void ratio of soil. According to the method used by Gao et al. [40], during the soil compression process, the basic physical parameters such as the dynamic viscosity coefficient of water, and the weight of free water are constant; only the permeability coefficient and void ratio are changing. Therefore, these constant
TABLE 7: Permeability coefficient at various consolidation pressures.

\begin{tabular}{lcc}
\hline $\begin{array}{l}\text { Consolidation } \\
\text { stress ratio } K_{c}\end{array}$ & $\begin{array}{c}\text { Consolidation stress } \\
(\mathrm{kPa})\end{array}$ & $\begin{array}{c}\text { Average permeability } \\
\text { coefficient } k\left(10^{-5} \mathrm{~cm} / \mathrm{s}\right)\end{array}$ \\
\hline \multirow{3}{*}{1} & 25 & 1.504 \\
& 50 & 1.140 \\
& 75 & 1.103 \\
& 100 & 0.850 \\
\hline \multirow{3}{*}{1.3} & 25 & 0.802 \\
& 50 & 0.650 \\
& 75 & 0.615 \\
& 100 & 0.513 \\
\hline \multirow{3}{*}{1.5} & 25 & 0.776 \\
& 50 & 0.604 \\
& 75 & 0.563 \\
& 100 & 0.476 \\
\hline
\end{tabular}

physical parameters can be expressed by the initial permeability coefficient $k_{0}$ and the initial porosity ratio $e_{0}$. Equation (11) yields

$$
\frac{\gamma_{w z} R^{2}}{8 \eta}=k_{0} \frac{1+e_{0}}{e_{0}} .
$$

Substituting Equation (12) into Equation (11), the permeability coefficient of soil was obtained as Equation (13). 


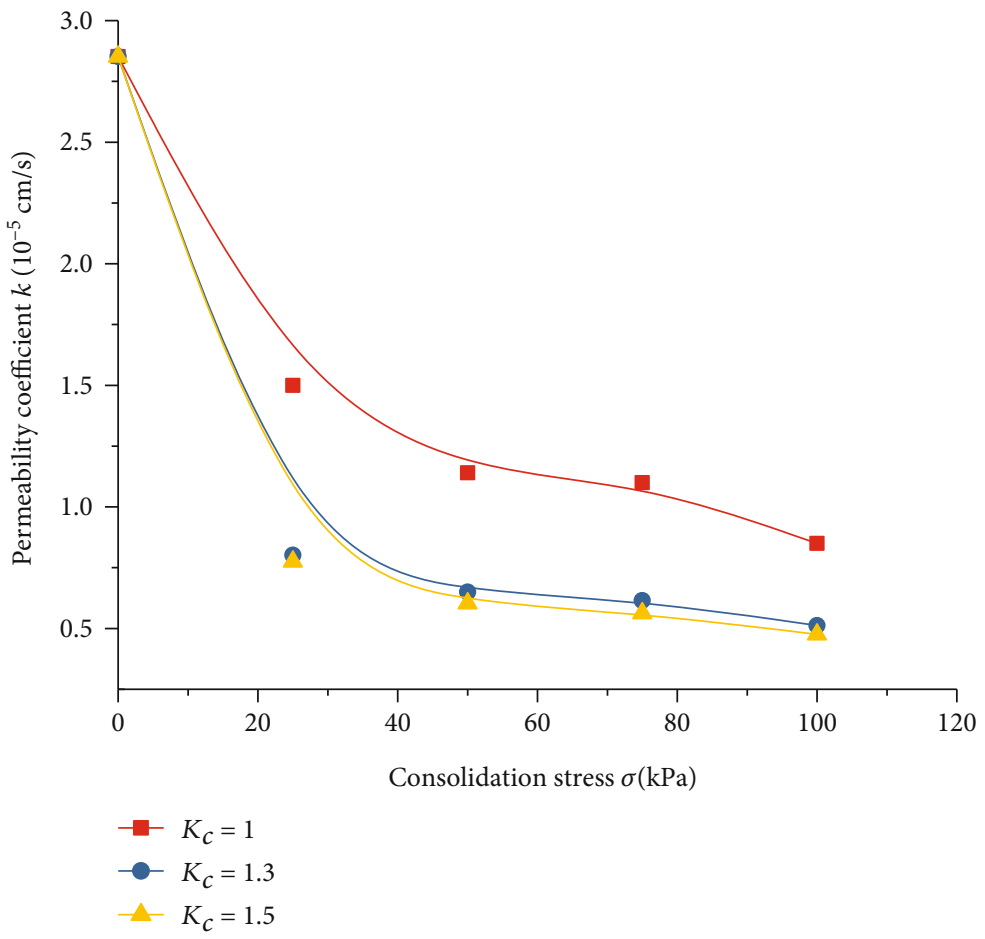

FIGURE 13: The curve of permeability coefficient of overconsolidation clay with consolidation pressure at different consolidation stress ratios.

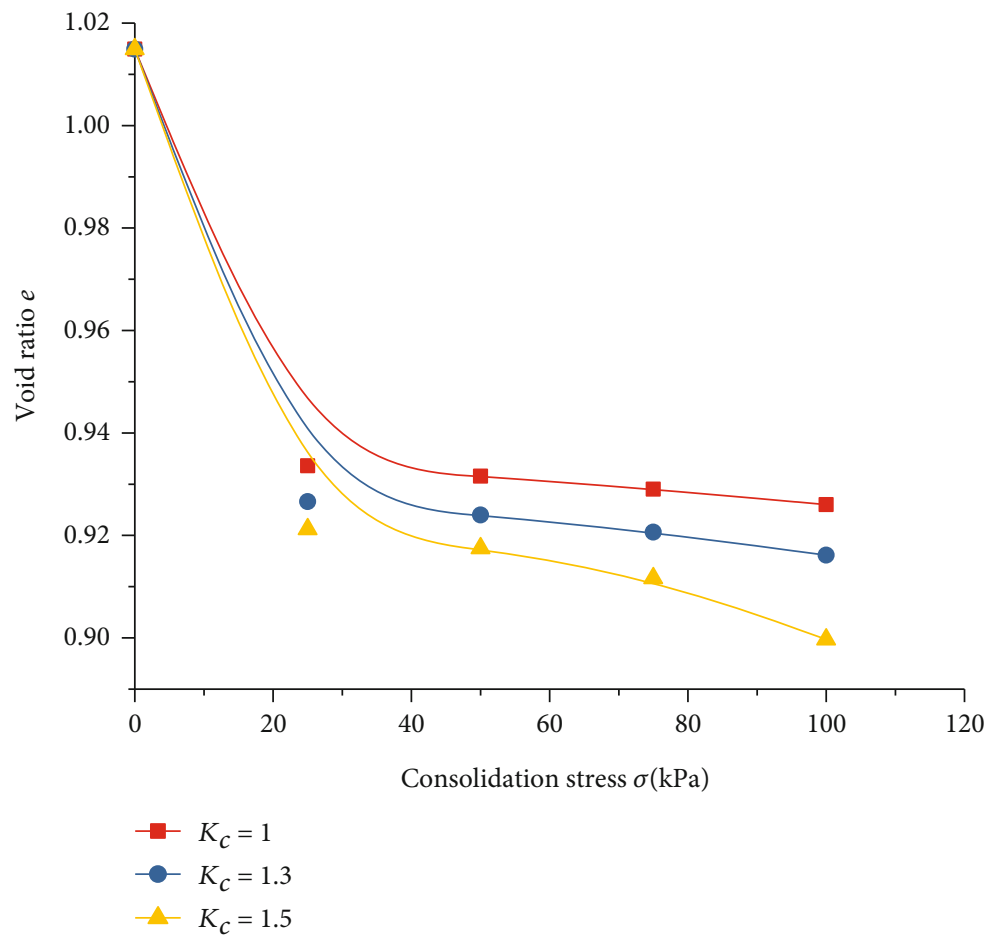

FIGURE 14: The curve of the void ratio of overconsolidation clay with consolidation pressure at different consolidation stress ratios. 
TABLE 8: Calculation results of deformation parameters of overconsolidation clay during consolidation.

\begin{tabular}{|c|c|c|c|c|c|c|}
\hline $\begin{array}{l}\text { Consolidation } \\
\text { stress ratio } K_{c}\end{array}$ & $\begin{array}{l}\text { Consolidation } \\
\text { stress }(\mathrm{kPa})\end{array}$ & $\begin{array}{c}\text { Sample's } \\
\text { compression } \\
(\mathrm{mm})\end{array}$ & $\begin{array}{l}\text { Sample's height after } \\
\text { compression }(\mathrm{mm})\end{array}$ & $\begin{array}{l}\text { Void } \\
\text { ratio } e\end{array}$ & $\begin{array}{c}\text { Compression } \\
\text { coefficient }\left(\mathrm{MPa}^{-1}\right)\end{array}$ & $\begin{array}{l}\text { Compression } \\
\text { modulus }(\mathrm{MPa})\end{array}$ \\
\hline \multirow{4}{*}{1} & 25 & 3.23 & 76.76 & 0.934 & 3.25 & 0.62 \\
\hline & 50 & 3.31 & 76.68 & 0.932 & 0.08 & 25.00 \\
\hline & 75 & 3.41 & 76.58 & 0.929 & 0.10 & 20.00 \\
\hline & 100 & 3.53 & 76.46 & 0.926 & 0.12 & 16.66 \\
\hline \multirow{4}{*}{1.3} & 25 & 3.51 & 76.48 & 0.927 & 3.53 & 0.57 \\
\hline & 50 & 3.61 & 76.38 & 0.924 & 0.10 & 19.38 \\
\hline & 75 & 3.74 & 76.25 & 0.921 & 0.13 & 15.04 \\
\hline & 100 & 3.92 & 76.07 & 0.916 & 0.18 & 11.20 \\
\hline \multirow{4}{*}{1.5} & 25 & 3.72 & 76.27 & 0.921 & 3.75 & 0.54 \\
\hline & 50 & 3.87 & 76.12 & 0.918 & 0.15 & 13.62 \\
\hline & 75 & 4.10 & 75.89 & 0.912 & 0.23 & 8.61 \\
\hline & 100 & 4.57 & 75.42 & 0.900 & 0.48 & 4.22 \\
\hline
\end{tabular}

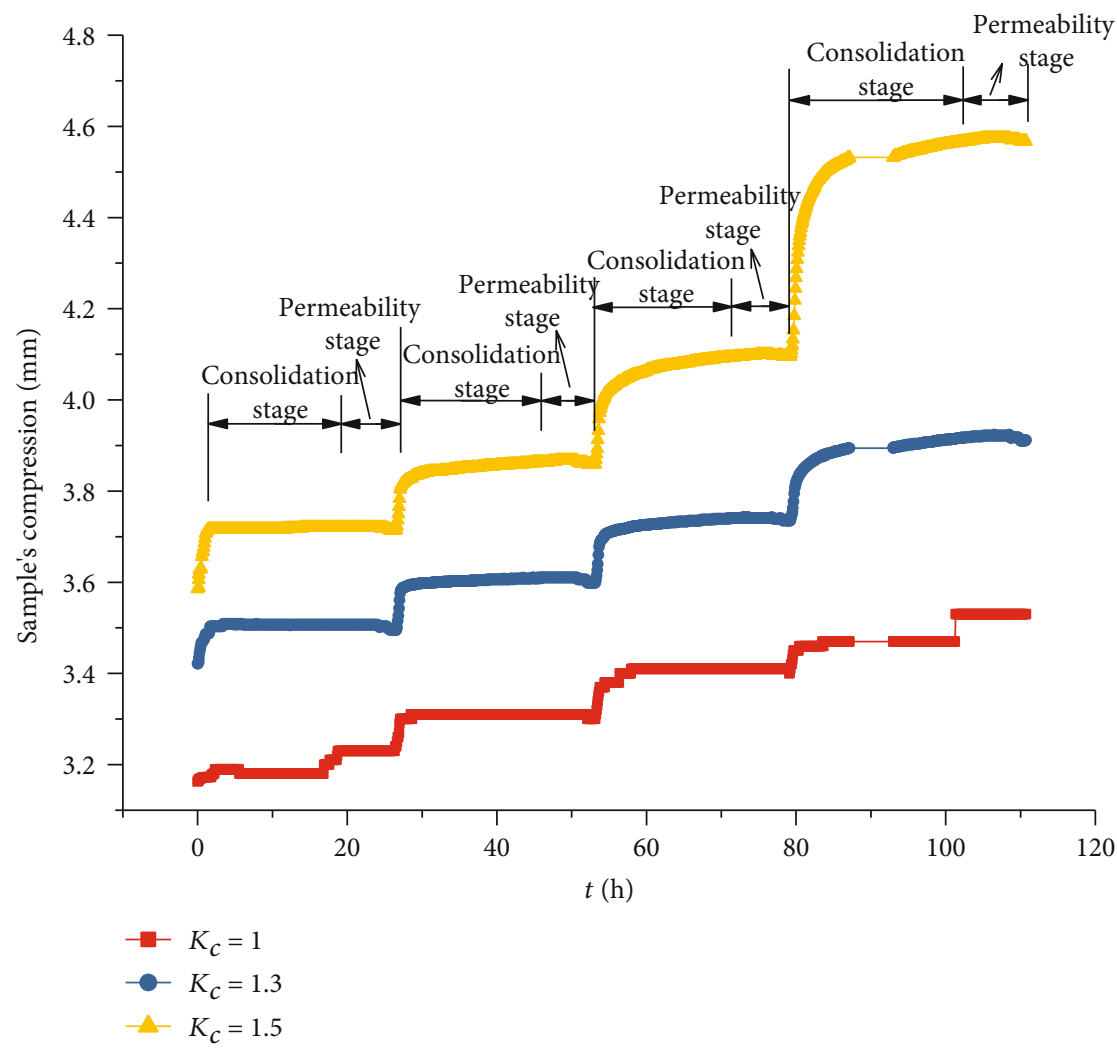

FIGURE 15: The curve of overconsolidation clay compression with time at different consolidation stress ratios. 


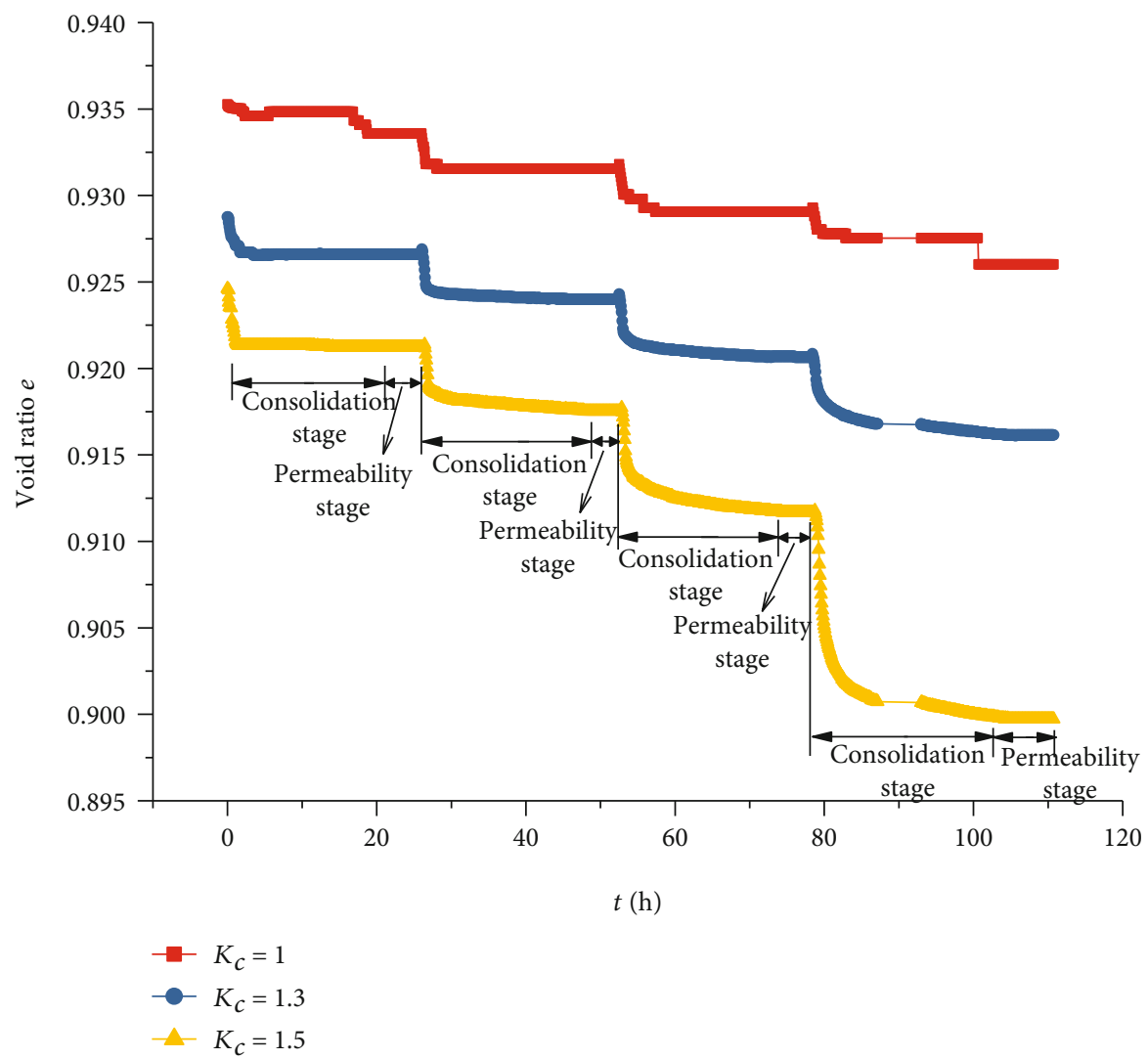

FIgURE 16: The curve of overconsolidation void ratio with time at different consolidation stress ratios.

TABLE 9: Stress calculations of overconsolidation clay.

\begin{tabular}{lccc}
\hline Stress state & $\sigma(\mathrm{kPa})$ & $\sigma_{c z}(\mathrm{kPa})$ & $\sigma_{d v}(\mathrm{kPa})$ \\
\hline \multirow{3}{*}{ Overconsolidation } & 25 & & -90 \\
& 50 & \multirow{2}{*}{115} & -65 \\
& 75 & & -40 \\
& 100 & & -15 \\
\hline
\end{tabular}

$$
k=k_{0} \frac{1+e_{0}}{e_{0}} \frac{e}{1+e} .
$$

For normally consolidated soil, it is assumed that the selfweight stress acting on the midpoint of the soil layer is $\sigma_{0}$, the corresponding initial void ratio is $e_{0}$, and the additional stress is $\Delta \sigma$; then actual stress is $\left(e_{0}+\Delta \sigma\right)$, and the corresponding void ratio is

$$
e=e_{0}-C_{c} \lg \frac{\sigma_{0}+\Delta \sigma}{\sigma_{0}}
$$

Submitting Equation (14) into Equation (13), the permeability coefficient equation for one-dimensional consolidation of normally consolidated soil was obtained as

$$
k=k_{0} \frac{1+e_{0}}{e_{0}} \frac{e_{0}-C_{c} \lg \left(\left(\sigma_{0}+\Delta \sigma\right) / \sigma_{0}\right)}{1+e_{0}-C_{c} \lg \left(\left(\sigma_{0}+\Delta \sigma\right) / \sigma_{0}\right)}
$$

(3) When expressed by the consolidation degree permeability equation, there was

$$
k=C_{v} \gamma_{w z} \frac{a_{v}}{1+e}
$$

where $C_{v}$ is the consolidation coefficient $\left(\mathrm{cm}^{2} / \mathrm{s}\right) ; \gamma_{w z}$ is the weight of free water $\left(\mathrm{kN} / \mathrm{m}^{3}\right)$; and $a_{v}$ is the compression coefficient $\left(\mathrm{MPa}^{-1}\right)$

In the same way as the Stokes equation, the equation of the permeability coefficient of normally consolidated soil under one-dimensional consolidation can be obtained as

$$
k=k_{0} \frac{1+e_{0}}{1+e_{0}-C_{c} \lg \left(\left(\sigma_{0}+\Delta \sigma\right) / \sigma_{0}\right)} .
$$

According to the measured results of one-dimensional consolidation permeability tests and Equations (9), (10), (15), and (17), the comparison between the predicted value and the measured value of the permeability coefficient of normally consolidated saturated clay can be obtained as shown in Figure 21. 


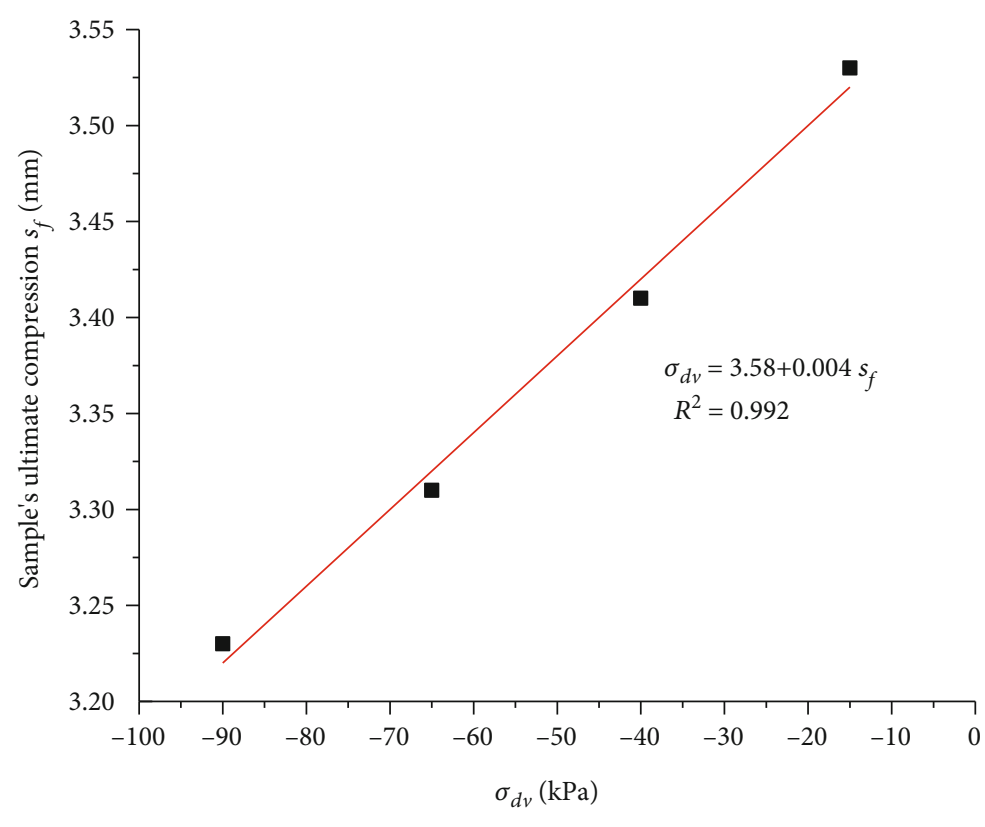

$K_{c}=1$

- Test results

Fitted curve

FIGURE 17: The relation curve between overconsolidation clay ultimate compression and stress difference.

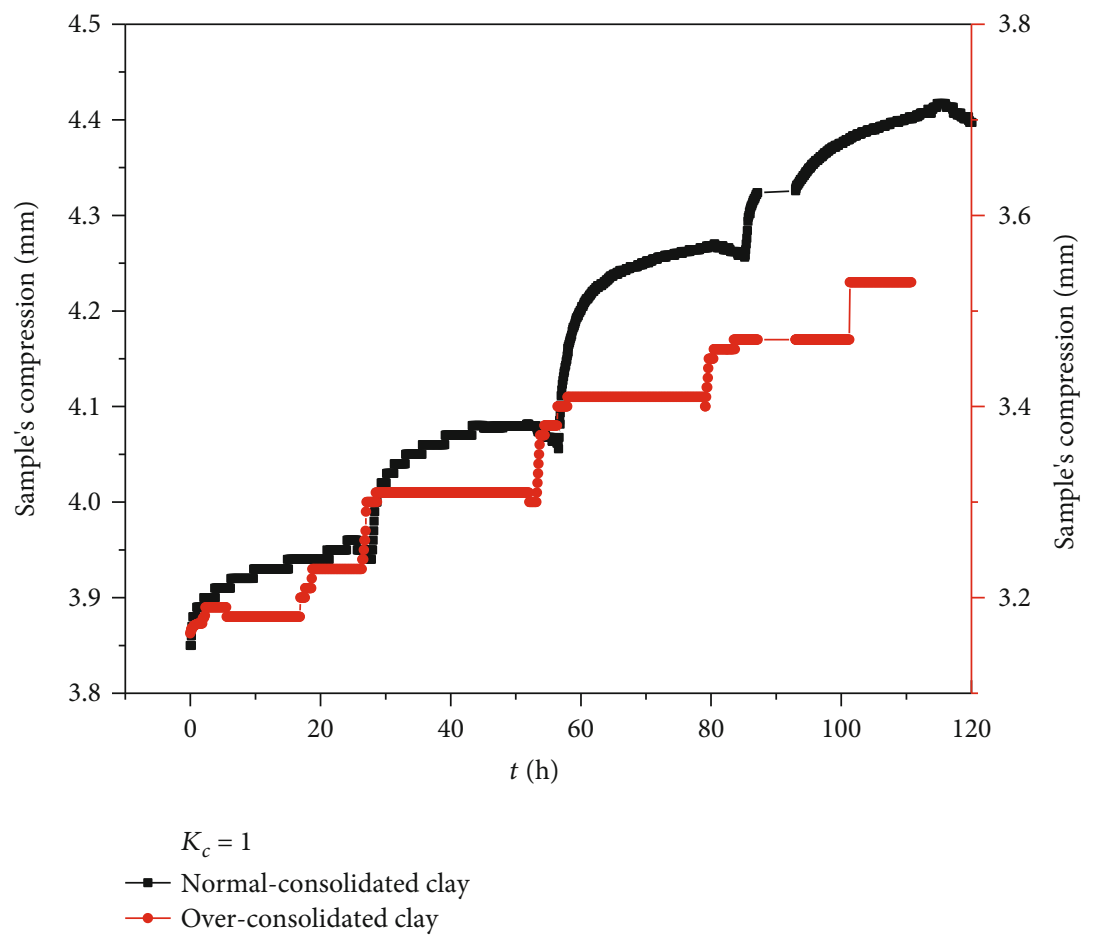

FIGURE 18: The curve of compression with time considering the influence of stress history. 


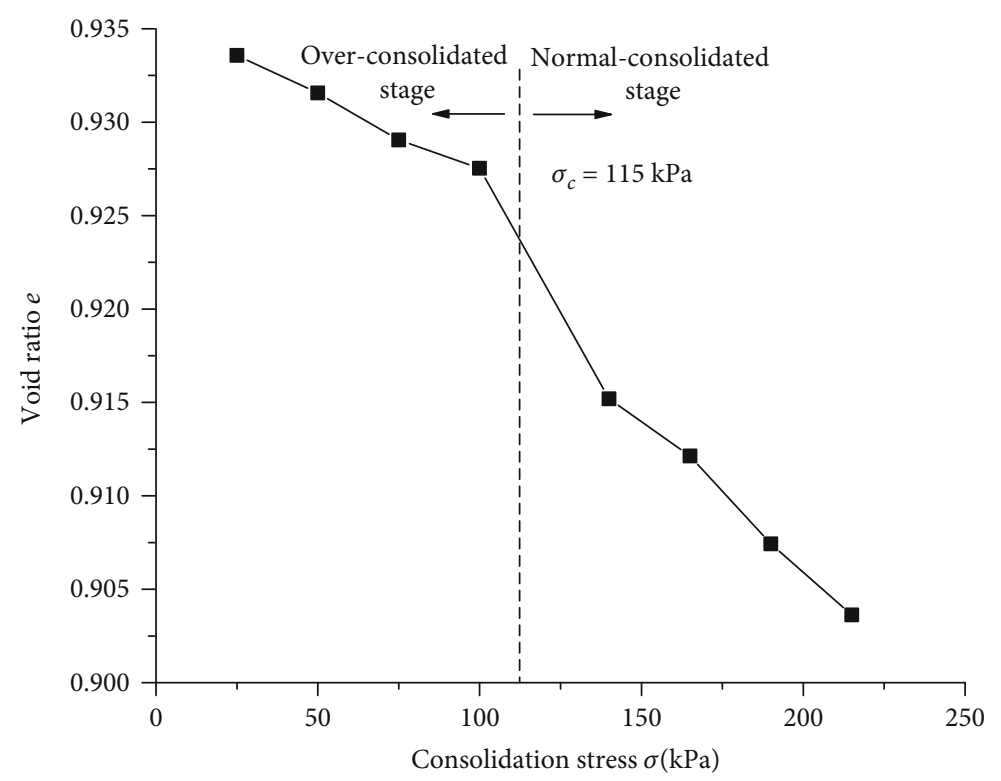

FIGURE 19: Variation curve of the void ratio with consolidation pressure during one-dimensional consolidation of normally and overconsolidation saturated clays.

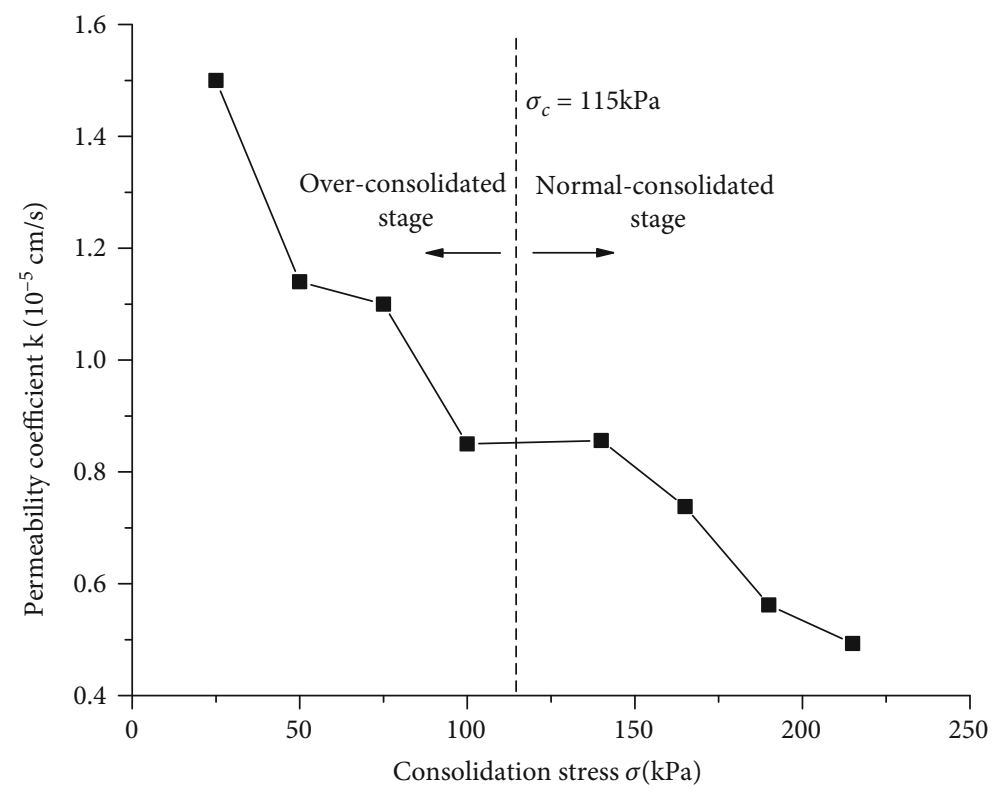

FIGURE 20: Variation curve of permeability coefficient with consolidation pressure during one-dimensional consolidation of normally and overconsolidation saturated clays.

It was found in Figure 21 that the predicted values of the permeability coefficient and the measured value were consistent with the change of the consolidation stress. The measured value of permeability coefficient was in the order of $10^{-5} \sim 10^{-6}$, while the permeability coefficient calculated by Stokes equation and consolidation degree equation was in the order of $10^{-5}$, which was quite different from the measured value. The calculated values of the modified Darcy's permeability coefficient equation and modified Kozeny-Carman's permeability coefficient equation proposed by Gao et al. [40] were close to the measured values. Besides, it can be seen from the figure that the permeability coefficient calculated by the modified Kozeny-Carman's permeability coefficient equation is almost coincided with the measured value. Therefore, it was more appropriate to use the modified KozenyCarman's permeability coefficient equation to predict the saturated clay permeability coefficient in Luochuan. 


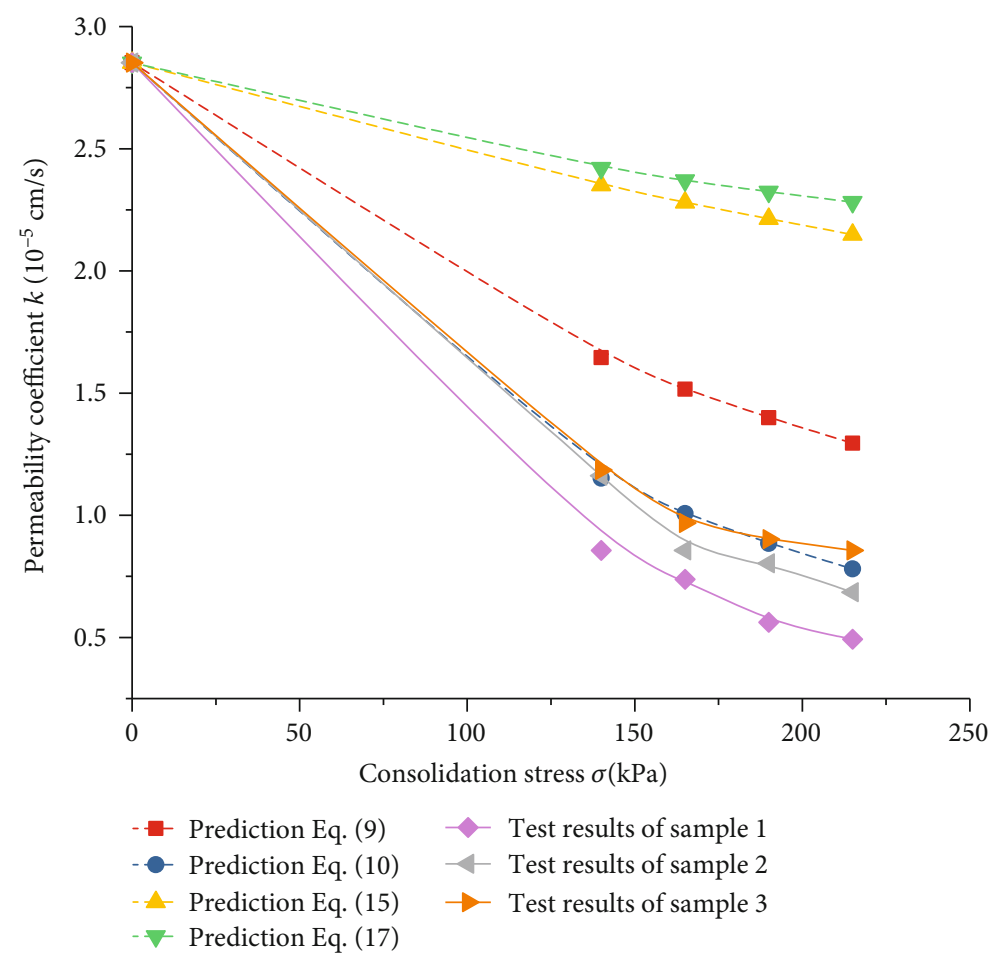

FIgURE 21: The comparison of the measured and predicted values of one-dimensional consolidation permeability coefficient of normally consolidated soil.

\section{Conclusion}

In this study, a series of one-dimensional consolidation permeability tests under different consolidation stress ratio $K_{c}$ and different stress history were carried out. Moreover, a model for predicting the permeability coefficient of the saturated clay in Luochuan, Shaanxi, was recommended by comparing several models. The following conclusions can be drawn:

(1) The permeability coefficient and void ratio of normally and overconsolidation saturated clay decreased with the increase of $K_{c}$, and the amount of sample's compression increased with the increase of $K_{c}$. When $K_{c}=1,1.3$, and 1.5 , the corresponding amounts of sample's final compression of normally consolidated soil were $4.43,5.52$, and $7.17 \mathrm{~mm}$, and those of overconsolidated soil were $3.53,3.92$, and $4.57 \mathrm{~mm}$

(2) Fitting the difference $\sigma_{d v}$ between the consolidation pressure $\sigma$ and the soil self-weight stress $\sigma_{c z}$ with the amount of final sample's compression $s_{f}$, it was concluded that the stress difference $\sigma_{d v}$ between the consolidation pressure and the self-weight stress of the soil layer and the amount of final compression under each consolidation pressure had a good linear relationship. After knowing the self-weight stress of the soil, the amount of final sample's compression can be predicted more accurately, which had an important application value for the engineering
(3) The compressibility and permeability of the soil in the overconsolidation stage are much smaller than that in the normally consolidation state under the same consolidation stress ratio but different consolidation states. Meanwhile, the amount of compression of overconsolidated saturated clay was less than that of normally consolidated saturated clay during the same consolidation time; that is, the amount of final sample's compression of overconsolidated soil was $3.53 \mathrm{~mm}$, while that of normally consolidated soil was $4.43 \mathrm{~mm}$ under the condition of $K_{c}=1$

(4) The permeability coefficient of Luochuan saturated clay in Shaanxi was predicted using the modified Darcy's permeability coefficient equation, the modified Kozeny-Carman's permeability coefficient equation, the Stokes flow permeability coefficient equation, and the consolidation degree permeability equation. The results showed that the calculated permeability coefficient of the modified Kozeny-Carman's permeability coefficient equation was in good agreement with the measured value. Therefore, it was recommended to use the modified Kozeny-Carman's equation to predict the permeability coefficient of Luochuan saturated clay during one-dimensional consolidation

\section{Data Availability}

The data used to support the findings of this study are available from the corresponding author upon request. 


\section{Conflicts of Interest}

The authors declare that they have no known competing financial interests or personal relationships that could have appeared to influence the work reported in this paper.

\section{Authors' Contributions}

Le Zhang is responsible for the investigation, testing, conceptualization, software, and writing of the original draft. Faning Dang is involved in the conceptualization and methodology. Jun Gao is also involved in the methodology and analyzed the data. Jiulong Ding performed the tests.

\section{Acknowledgments}

This study is sponsored by the National Natural Science Foundation of China (Nos. 51979225 and 51679199), the Special Funds for Public Industry Research Projects of the Ministry of Water Resources (No. 201501034-04), the Key Laboratory for Science and Technology Coordination \& Innovation Projects of Shaanxi Province (No. 2014SZS15Z01), and the Natural Science Foundation of Shaanxi Province (No. 2020JQ-584). The authors gratefully acknowledge the financial and technical support from these sources.

\section{References}

[1] L. Y. Sun, One-Dimensional Consolidation Experiment and Theory of Saturated Clay Based on Non-Darcy Flow, Dissertation, Zhengzhou University, 2011.

[2] C. Wu, J. Chu, S. Wu, L. Cheng, and L. A. van Paassen, "Microbially induced calcite precipitation along a circular flow channel under a constant flow condition," Acta Geotechnica, vol. 14, no. 3, pp. 673-683, 2018.

[3] C. Wu, J. Chu, S. Wu, and Y. Hong, "3D characterization of microbially induced carbonate precipitation in rock fracture and the resulted permeability reduction," Engineering Geology, vol. 249, pp. 23-30, 2018.

[4] E. H. Davis and G. P. Raymond, "A non-linear theory of consolidation,” Geotechnique, vol. 15, no. 2, pp. 161-173, 1965.

[5] K. H. Xie, X. Y. Xie, and W. Jiang, "A study on onedimensional nonlinear consolidation of double-layered soil," Computers and Geotechnics, vol. 29, no. 2, pp. 151-168, 2002.

[6] J. Y. Shi, L. A. Yang, W. B. Zhao, and Y. X. Liu, "Research of one-dimensional consolidation theory considering nonlinear characteristics of soil," Journal of Hohai University, vol. 29, no. 1, pp. 1-5, 2001.

[7] S. Dumais and J. M. Konrad, "One-dimensional large-strain thaw consolidation using nonlinear effective stress - void ratio - hydraulic conductivity relationships," Canadian Geotechnical Journal, vol. 55, no. 3, pp. 414-426, 2018.

[8] J. H. Yin and W. Q. Feng, "A new simplified method and its verification for calculation of consolidation settlement of a clayey soil with creep," Canadian Geotechnical Journal, vol. 54, no. 3, pp. 333-347, 2017.

[9] W. Q. Feng and J. H. Yin, "Development and verification of a new simplified method for calculating settlement of a thick soil layer with nonlinear compressibility and creep," International Journal of Geomechanics, vol. 20, no. 3, article 04019184, 2020.
[10] Q. Liu, Y. B. Deng, and T. Y. Wang, "One-dimensional nonlinear consolidation theory for soft ground considering secondary consolidation and the thermal effect," Computers and Geotechnics, vol. 104, pp. 22-28, 2018.

[11] C. Q. Xia, A. F. Hu, J. Cui, W. X. Lv, and K. H. Xie, “Analytical solutions for one-dimensional nonlinear consolidation of saturated soft layered soils," Rock and Soil Mechanics, vol. 39, no. 8, pp. 2858-2864, 2018.

[12] C. X. Li, J. S. Huang, L. Z. Wu, L. Z. Lu, J. F. Lu, and C. Q. Xia, "Approximate analytical solutions for one-dimensional consolidation of a clay layer with variable compressibility and permeability under a ramp loading," International Journal of Geomechanics, vol. 18, no. 11, article 06018032, 2018.

[13] K. R. Lekha, N. R. Krishnaswamy, and P. Basak, "Consolidation of clays for variable permeability and compressibility," Journal of Geotechnical and Geoenviromental Engineering, vol. 129, no. 11, pp. 1001-1009, 2003.

[14] N. Abbasi, H. Rahimi, A. A. Javadi, and A. Fakher, "Finite difference approach for consolidation with variable compressibility and permeability," Computers and Geotechnics, vol. 34, no. 1, pp. 41-52, 2007.

[15] A. Mishra and N. R. Patra, "Long-term response of consolidating soft clays around a pile considering non-Darcian flow," International Journal of Geomechanics, vol. 19, no. 6, article 04019040, 2019.

[16] Z. Y. Liu, Y. Y. Xia, M. S. Shi, J. C. Zhang, and X. M. Zhu, "Numerical simulation and experiment study on the characteristics of non-Darcian flow and rheological consolidation of saturated clay," Water, vol. 11, no. 7, article 1385, 2019.

[17] X. D. Zhao and W. H. Gong, "Numerical solution of nonlinear large strain consolidation based on non-Darcian flow," Mathematical Problems in Engineering, vol. 2019, Article ID 745068, 14 pages, 2019.

[18] C. X. Li, C. Xu, and K. H. Xie, "Nonlinear consolidation of clayed soil considering non-Darcy flow and stress history," Rock and Soil Mechanics, vol. 38, no. 1, pp. 91-100, 2017.

[19] Y. Z. Jiu, Z. Y. Liu, J. C. Yue, and L. Y. Sun, “One-dimensional consolidation with a consideration of non-Darcy flow and selfgravity stress," Journal of Tongji University (Natural Science), vol. 40, no. 4, pp. 541-548, 2012.

[20] C. X. Li, C. J. Wang, M. M. Lu, J. F. Lu, and K. H. Xie, “Onedimensional large-strain consolidation of soft clay with nonDarcian flow and nonlinear compression and permeability of soil," Journal of Central South University, vol. 24, no. 4, pp. 967-976, 2017.

[21] S. Sica, L. Pagano, and A. Modaressi, "Influence of past loading history on the seismic response of earth dams," Computers and Geotechnics, vol. 35, no. 1, pp. 61-85, 2008.

[22] X. B. Li, K. H. Xie, and F. Q. Chen, "One dimensional consolidation and permeability tests considering stress history and rheological characteristic of soft soils," Journal of Hydraulic Engineering, vol. 44, no. 1, pp. 18-25, 2013.

[23] K. H. Xie, J. B. Wen, H. W. Ying, and A. F. Hu, "One-dimensional consolidation theory of double-layered soil considering effects of stress history," Journal of Zhejiang University (Engineering Science), vol. 41, no. 7, pp. 1126-1131, 2007.

[24] W. Q. Lv, Z. L. Dong, P. S. Chen, and H. H. Mo, "Research on relationship between permeability coefficient and consolidation stress of normal consolidation clay," Rock and Soil Mechanics, vol. 30, no. 3, pp. 769-773, 2009. 
[25] R. L. Schiffman, "Consolidation of soil under time-dependent loading and varying permeability," Proceedings of the Highway Research Board, vol. 37, pp. 584-617, 1958.

[26] R. E. Olson, "Consolidation under time-dependent loading," Journal of the Geotechnical Engineering Division, vol. 103, no. 1, pp. 55-60, 1977.

[27] J. C. Liu and Q. Ma, One-Dimensional Consolidation of Soft Ground with Impeded Boundaries under Depth-Dependent Ramp Load, First International Symposium on Pavement and Geotechnical Engineering for Transportation Infrastructure, 2013.

[28] M. Sun, M. F. Zong, S. J. Ma, W. B. Wu, and R. Z. Liang, "Analytical solution for one-dimensional consolidation of soil with exponentially time-growing drainage boundary under a ramp load," Mathematical Problems in Engineering, vol. 2018, Article ID 9385615, 10 pages, 2018.

[29] Y. Tian, W. Wu, G. Jiang et al., "One-dimensional consolidation of soil under multistage load based on continuous drainage boundary," International Journal for Numerical and Analytical Methods in Geomechanics, vol. 44, no. 8, pp. 1170-1183, 2020.

[30] W. Q. Feng, J. H. Yin, W. B. Chen, D. Y. Tan, and P. C. Wu, "A new simplified method for calculating consolidation settlement of multi-layer soft soils with creep under multi-stage ramp loading," Engineering Geology, vol. 264, article 105322, 2020.

[31] S. F. Zou, J. Z. Li, Z. J. Wang, L. Lan, W. J. Wang, and X. Y. Xie, "Seepage test and empirical models for soils based on GDS apparatus," Journal of Zhejiang University (Engineering Science), vol. 51, no. 5, pp. 856-862, 2017.

[32] T. Qi, Theoretical and Experimental Studies on Onedimensional Nonlinear Consolidation of Soft Soil, Dissertation, Zhejiang University, 2008.

[33] J. B. Wen, Study on One-dimensional Consolidation Theory of Layered Soils Considering the Effect of Stress History, Dissertation, Zhejiang University, 2007.

[34] C. L. Chen, C. M. Cao, F. Chu, and J. T. Wang, "Effects of consolidation stress ratio on pore water pressure characteristics of saturated intact loess under different stress paths," Journal of Xi'an University of Technology, vol. 25, no. 3, pp. 328-332, 2009.

[35] G. J. Cai, S. Y. Liu, and A. J. Puppala, "Predictions of coefficient of consolidation from CPTU dissipation tests in Quaternary clays," Bulletin of Engineering Geology and the Environment, vol. 77, no. 2, pp. 337-350, 2012.

[36] B. Li, Y. G. Fang, and Z. F. Ou, “Asymptotic solution for the one-dimensional nonlinear consolidation equation including the pore evolution effect," International Journal of Geomechanics, vol. 18, no. 10, article 04018125, 2018.

[37] H. Y. Hu, Study on One-dimensional Consolidation Theory of Saturated Soil Considering the Effect of Stress History, Dissertation, Zhejiang University, 2004.

[38] Y. Xue, T. Teng, F. Dang, Z. Ma, S. Wang, and H. Xue, "Productivity analysis of fractured wells in reservoir of hydrogen and carbon based on dual-porosity medium model," International Journal of Hydrogen Energy, vol. 45, no. 39, pp. 20240-20249, 2019.
[39] J. Liu, X. Liang, Y. Xue, K. Yao, and Y. Fu, "Numerical evaluation on multiphase flow and heat transfer during thermal stimulation enhanced shale gas recovery," Applied Thermal Engineering, vol. 178, 2020.

[40] J. Gao, F. N. Dang, J. L. Ding, C. Yang, and L. Zhang, "Research on soft soil consolidation calculation method considering the impacts of initial consolidation state," Chinese Journal of Rock Mechanics and Engineering, vol. 38, no. Supp 1, pp. 3189-3196, 2019. 